\title{
ANALYSIS STUDY OF EGYPTIAN FRESH GRAPE EXPORTS TO ITS MOST IMPORTANT INTERNATIONAL MARKETS
}

\author{
HEND NABIL MOHAMED
}

Agricultural Economics Research Institute, ARC, Dokki, Giza.

(Manuscript received 22 October 2018)

\begin{abstract}
$\mathrm{T}$ he development of Egyptian agricultural exports are one of the main pillars of agricultural sector.Grapes is one of the most important horticultural export crops in Egypt. The value of Grapes exports is about LE 1922 million representing about $8.2 \%$ of the value of agricultural exports for the period (2014-2016).

The results showed the following:

The total area of export grape varieties increased from about 3671 fedden in 2001 to about 48800 fedden in 2016, it represent about $14.5 \%$ of the total area of grapes as an average of the study period (2001-2016).

The results of the instability coefficients of the quantity of production of export grapes, the quantity of grape exports and the export price during the two periods (2001-2008), (2009-2016) indicate the stability of grape production and exports during the second study period compared to the first period Export in recent years.

The EU accounts for approximately 77.6 thousand tons of the total Egyptian exports of fresh grapes as an average for the period (2014-2016) representing about $68 \%$, this quantity represents about $4.8 \%$ only of the total imports of the European Union of fresh grapes.

The main importers of fresh Egyptian grapes are United Kingdom and Netherlands, which estimated at $31.5 \%, 20.1 \%$ respectively of the total quantity of Egyptian grape exports as an average for the period 20142016.

Chile is considered to be the most competitive market for Egyptian exports of fresh grapes as it shares with Egypt in the export season.

The total imports of the United Kingdom of fresh grapes amounted to 264 thousand tons as an average for the period (2014-2016). Germany achieved the best price competitiveness within the English market. The price index for Egyptian grapes reached 0.30 and thus is in good shape with the rest of the competing countries such as Chile and South Africa, with a price competitiveness index of 0.17 and 0.28 , respectively, the market penetration rate was around 0.088 , which indicates the difficulty of increasing exports of Egyptian grapes to the English market

Netherland's total imports of fresh grapes reached 351 thousand tons as an average for the period 2014-2016. Chile achieved the best price competition within the Dutch market. The Egyptian grape price index reached 0.47 , and the market penetration rate reached 0.288 Indicates that there is a great opportunity to increase the amount of exports of Egyptian grapes to the Dutch market.

The most important factors affecting the quantity of Egyptian exports of fresh grapes to UK were the quantity of fresh grapes imports to UK.

The most important factors affecting the quantity of Egyptian exports of fresh grapes to Netherlands were the quantity of fresh grapes imports to Dutch market.

So the research recommended followings:

1- Produce early varieties of maturity

2. Study the foreign markets well and open new markets

3 - Attention to training and awareness of producers and exporters with quality specifications and health requirements

4. Studying the marketing behavior of export grapes
\end{abstract}




\title{
دراسة تحليلية لصادرات العنب \\ الطازج المصرى بأهم أسواقة العالمية
}

\author{
هند نبيل محمد يوسف \\ معهُ بحوث الاقتصاد الزراعي - مركز البحوث الزر اعية - الدقي - الجيزة. \\ المقدمة
}

تعد تتمية الصادر ات من القضايا الأساسية النى تهتم بها الدول لكونها المصــدر الأساسـى

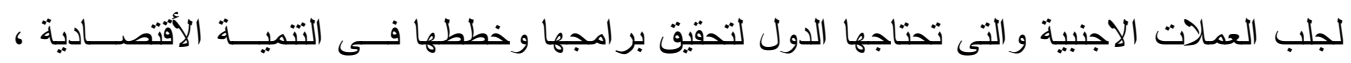

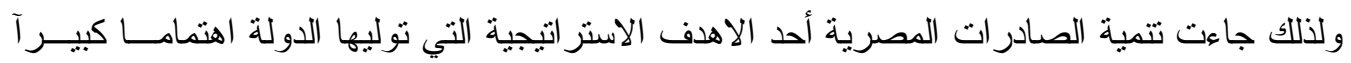

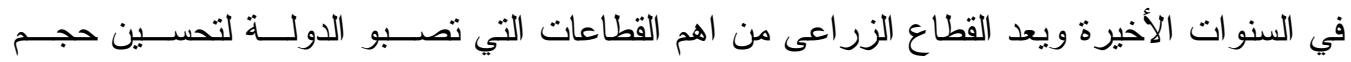
الصادر ات منه في المستقبل وفى ظل المتغيرات الدولية الجديدة بعد نطبيق اتفاقية الجات و التي فتحت التحن

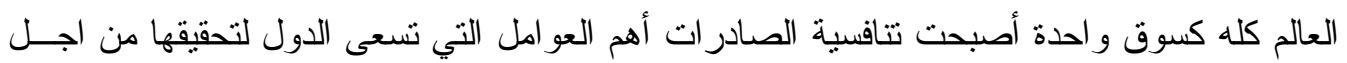
ان تغزو منتجاتها الأسواق العالمية ، وقد جاءت تتمية الصادرات الزر اعية المصرية مــن المحسـاور

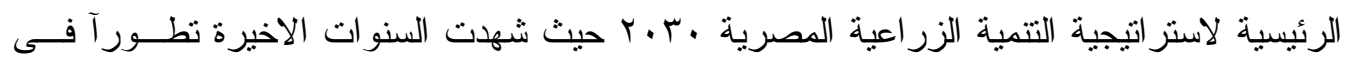

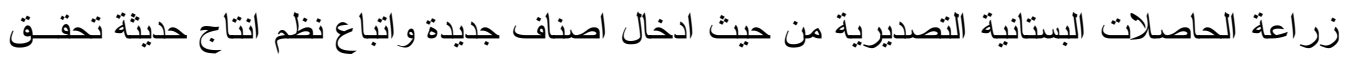
تتافسية افضل للحاصلات البستانية المصرية من حيث مو اصفات الجودة وتوقيتات الدخول للاســـواق

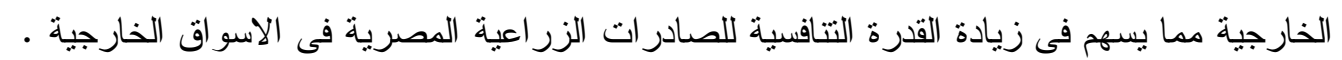
ويعتبر العنب احد أهم المحاصيل البستانية التصديرية فى مصر حيث تبلغ قيمة صادر اتة نحو 1922

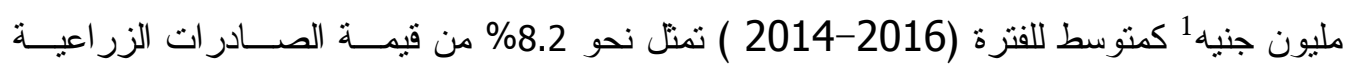
و البالغة نحو 23352 مليون جنيه.

\section{مشكلة البحث}

تتحصر مشكلة البحث فى أنه على الرغم من التز ايد المستمر فى مساحة وانتاج العنب فــى التى

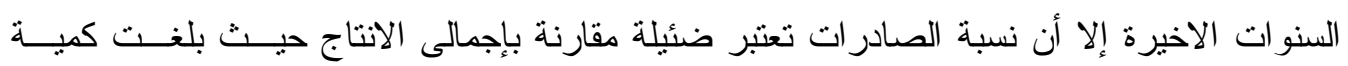

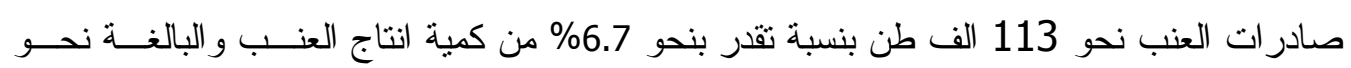
1691 الف طن عام 2016.

\section{الإذف من البحث}

در اسة أهم العو امل المؤثرة على كمية صادرات العنب الطازج المصرى من خلال الاتى لهن 1- در اسة الوضع الر اهن لانتاج أصناف العنب في مصر المحلى و التصدير.

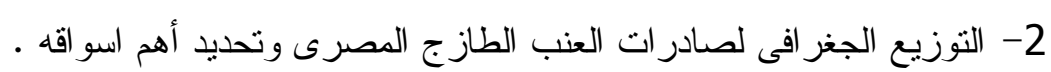

3- در اسة أهم النو افذ التسويقية لصادر ات العنب المصرى.

4- تقدير مؤشر ات تتافسية صادر ات العنب المصرى داخل أهم أسو اقه الخارجية. 


$$
\text { 5- تقدير دالة الطلب على صادر ات العنب المصرى فى أهم اسواقة الخارجية. }
$$

أعتمد البحث فى تحليله الاقتصادى على اساليب التحليل الاحصائى الوصفى و الكمى ، بالإضافة إلـى

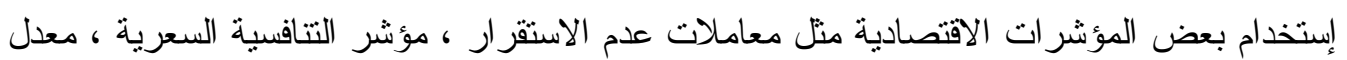
اختر اق السوق ، تقدير دالة الطلب على صادر ات العنب المصرى فى اهم أسو اقه الخارجية. مصادر البياتات

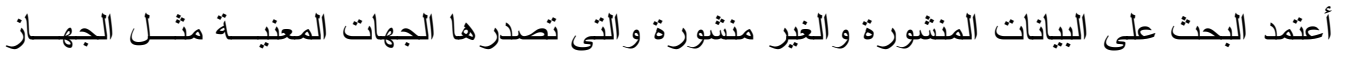

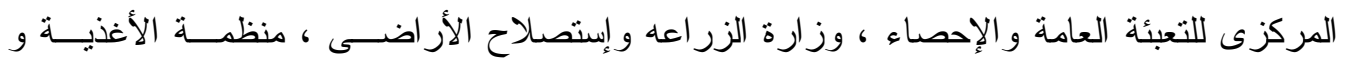
الزر اعه (F.A.O) ، الحجر الزر اعى ، قواعد بيانات التجارة الخارجية على (الانترنت). الإطار النظرى لبعض المؤشرات المستخدمة لقياس تنافسية الصادرات:

أ-مؤشرات التنافسية السعرية 1: : The Price Competetiveness Indicator و ويتم ذلك عن طريق حساب النسبة بين المتوسط المرجح لأسعار السلعة لأهم الدول المتتافسة فى سوق معين كـــل إلى سعر تصدير السلعة لكل دولة من هذه الدول فى هذا السوق وذللك باستخدام المعادلة التالية : $\mathrm{P}_{\mathrm{Cj}}$

$$
P_{A j}=\frac{P_{C j}}{P_{e j}}
$$

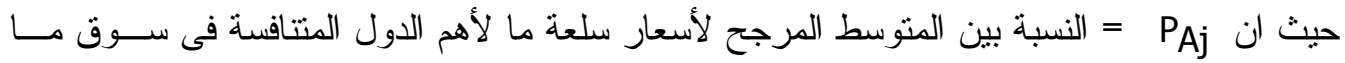
ككل إلى سعر تصدير كل دولة منتافسة لنفس السلعة فى هذا السوق.

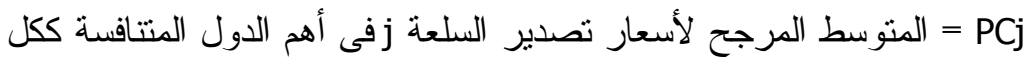

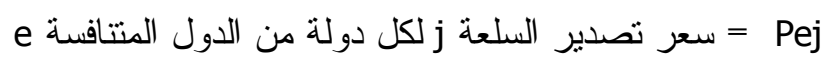

ب - تقدير الوضع النسبى لسعر مصر بالنسبة للاول المنافسة من خلال المعادلة الاتية: $P_{A j}-P_{A j \min }$

$$
\mathrm{R}_{A_{j}}=\frac{\mathrm{P}_{A j \text { max }}-\mathrm{P}_{A j \text { min }}}{{ }^{A j}-P_{A j}}
$$

حيث أن : RAj = الوضع النسبى لسعر السلعةز ( العنب ) من الدولة A بالنسبة للاول المنافسة

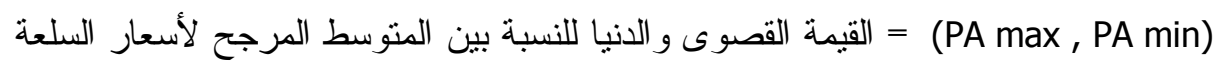

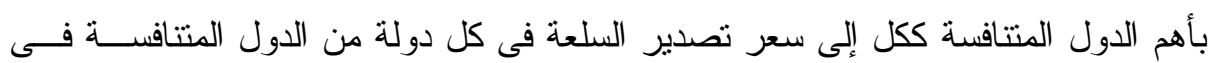

U.S Agency for international Development and Ministry of Economy and 1 foreign trade, "The International Competitiveness of Egypt in Perspective", Development Economic Policy Reform Analysis , Project (DEPRA) , Egypt , Cairo ,1998. 
وتتحصر القيمه الناتجة بين ( صفر ، 1 ) وكلما ارتفعت القيمة الناتجة دل ذلك على تحسن الوضـع

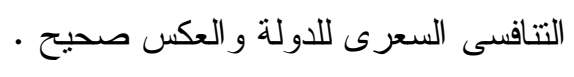

\section{Market Penetration Rate}

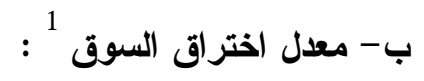

يعتبر معدل اختراق الاسواق مؤشرا هاما لقياس الأداء السوقى لدولة ما ، وهو عبارة عارة عن النسبة بين

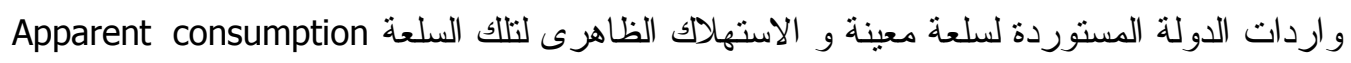
، ويمثل معدل اختراق الاسواق مقياسا لقابلية الاسواق لاستيعاب كميات اكبر مــن الــو اردات مـــن

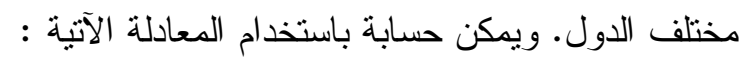

$\mathrm{I}_{\mathrm{jA}}$

$\mathrm{MPR}_{\mathrm{ij}}-=$

$$
Q_{i j}+I_{i j}-E_{i j}
$$$$
\text { حيث أن : }
$$

Market Penetration Rate معدل اختراق السوق i من السلعة = MPR

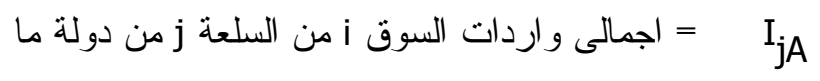

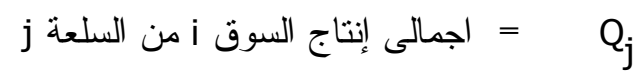

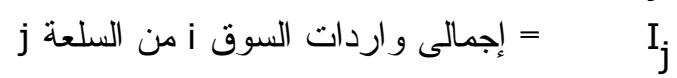

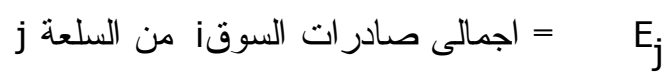

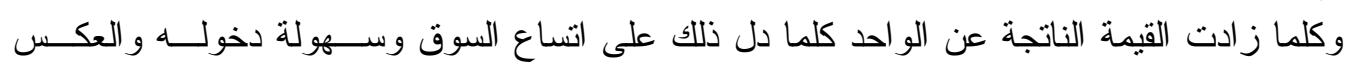

\section{الأهمية الاقتصادية لمحصول العنب :}

يعتبر محصول العنب من اهم محاصيل الفاكهة بعد محصول البرتقال مــن حيــث المســاحة

الكلية و التى قدرت بنحو 199 الف فدان2 تمثل نحو 11.94\% من اجمالى المساحة الكلية لمحاصـيل

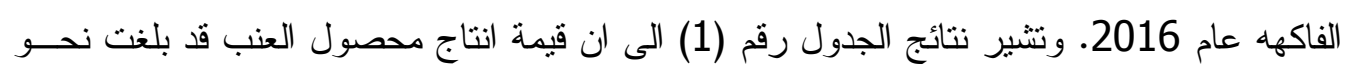

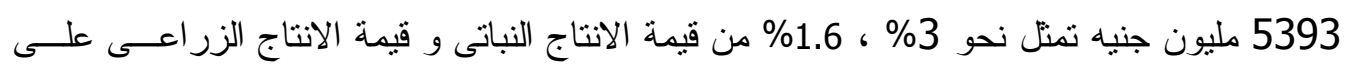

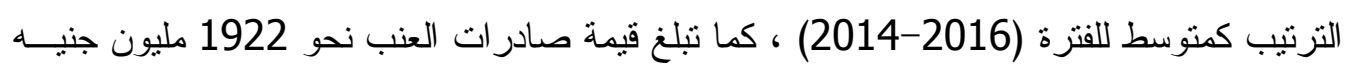
تمثل نحو 8.2\% من قيمة الصادرات الزر اعية كمتوسط لنفس الفترة.

U.S Agency for international Development and Ministry of Economy and ${ }^{1}$ foreign trade, Ibid. 
جدول رقم (1) : الأهمية الاقتصادية لمحصول العنب خلال الفترة (2016-2014) القيمة بالمليون جنيه

\begin{tabular}{|c|c|c|c|c|c|c|c|c|}
\hline$\%$ & الزادر الزية & قيمة صادر ات & $\%$ & قالزيمة الإنتاج & $\%$ & قيمة الانتاج & قيمة انتاج & السنو ات \\
\hline 8.3 & 20948 & 1738 & 1.6 & 305414 & 2.9 & 170953 & 4878 & 2014 \\
\hline 8.5 & 21822 & 1858 & 1.7 & 318332 & 3.1 & 175517 & 5401 & 2015 \\
\hline 7.9 & 27285 & 2169 & 1.7 & 356958 & 3.1 & 190595 & 5901 & 2016 \\
\hline 8.2 & 23352 & 1922 & 1.6 & 326901 & 3.0 & 179022 & 5393 & المتوسط \\
\hline
\end{tabular}

المصدر :(1): الجهاز المركزى للتعبئة العامة والإحصاء - قاعدة بيانات التجارة الخارجية. (2) : وزارة الزر اعة واستصلاح الار اضى - قطاع الشئون الاقتصادية - نشرة الدخل الزراعى - اعداد متفرقة .

\section{الأهمية النسبية لمحصول العنب من اجمالى محاصيل الفاكهة :}

يعتبر العنب من محاصيل الفاكهة التى تجود زر اعتها فى الأر اضى الجديدة و المستصلحة و و

يأتى محصول العنب فى المرتبة الثانية بين محاصيل الفاكهة بعد محصول البرتقال من حيث المساحة

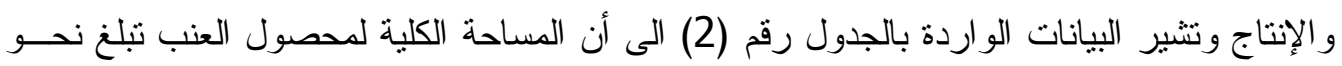

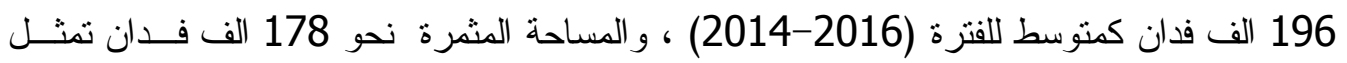

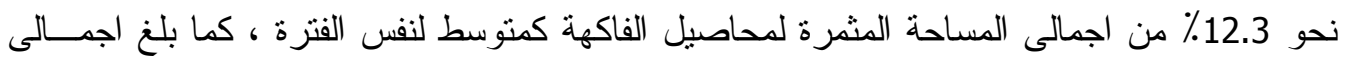

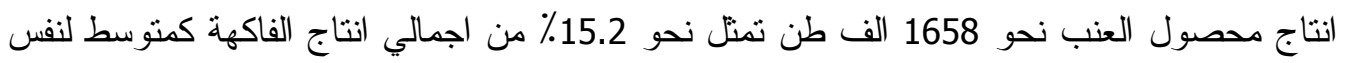

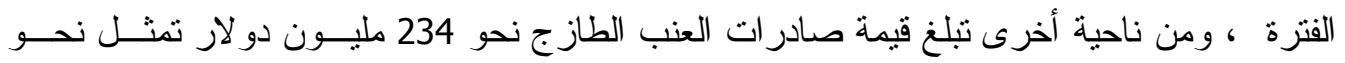
20.9 \% من إجمالى قيمة صادر ات الفاكهة و البالغة نحو 1124 مليون دو لار كمنوسط لنفس الفترة. جدول رقم (2): الاهمية النسبية لمحصول العنب من اجمالى محاصيل الفاكهة ولهة

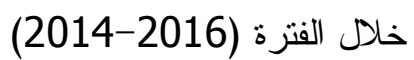

\begin{tabular}{|c|c|c|c|c|c|c|c|c|c|c|}
\hline $\begin{array}{c}(10) \\
(9) /(8) \\
\%\end{array}$ & 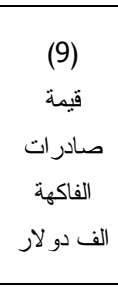 & صلقد & $\begin{array}{c}(7) \\
(6) /(5) \\
\%\end{array}$ & $\begin{array}{c}\text { انتاج الفاكهة } \\
\text { طن }\end{array}$ & $\begin{array}{c}\text { انتاج العنب } \\
\text { طن } \\
\text { العن }\end{array}$ & $\begin{array}{c}(4) \\
(3) /(2) \\
\%\end{array}$ & 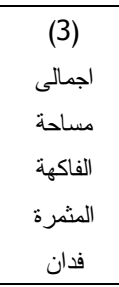 & 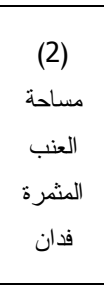 & فالعادة & السنو ات \\
\hline 23.3 & 1051694 & 245080 & 15.2 & 10527313 & 1596169 & 13.1 & 1310655 & 171882 & 192934 & 2014 \\
\hline 21.6 & 1123103 & 242897 & 15.1 & 11154076 & 1686706 & 13.2 & 1351561 & 178323 & 196993 & 2015 \\
\hline 17.8 & 1196063 & 212761 & 15.2 & 11129474 & 1691194 & 11.0 & 1668701 & 184254 & 199212 & 2016 \\
\hline 20.9 & 1123620 & 233579 & 15.2 & 10936954 & 1658023 & 12.3 & 1443639 & 178153 & 196380 & المتوسط \\
\hline
\end{tabular}

المصدر :جمعت وحسبت من بيانات: ا- وز ارة الزر اعة واستصلاح الار اضى ،قطاع الثئون الاقتصادية، نشرة الإحصاءات الزر اعية ،اعداد منقرقة.

2- United Nations Commodity Trade Statistics Database 


\section{مواصفات وأصناف عنب التصدير :}

تهدف استر اتيجية التتمية الزر اعة المصرية 2030 الى الاهتمام بالتصدير وزيــادة كميــة

الصادر ات الزر اعية المصرية وذلك من خلال تحسين طرق الانتاج و اتباع النظم التكنولوجية الحديثة وتحديث الاصناف المزروعة والتى تتو افق مع الاذواق العالمية من حيث مواصفات الجودة وتوقيتات الانتاج و التى تعتبر حزمة من البر امج التى تسمى الانتاج للتصدير من اجل زيادة القــدرة التتافسـية

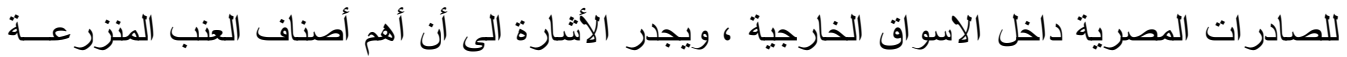

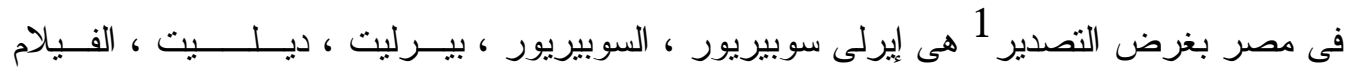

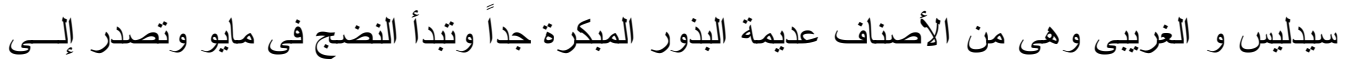

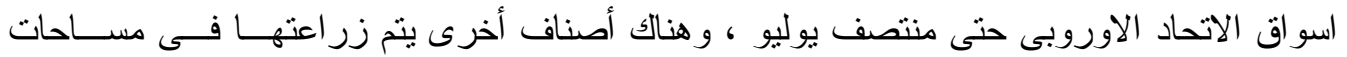

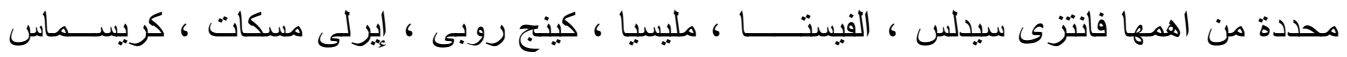

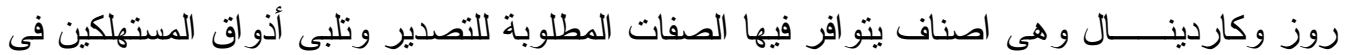
الاسواق الخارجية. مساحة وانتاج أهم اصناف العنب فى مصر : يزرع فى مصر اكثر من تسع أصناف عنب ما بين اصناف عنب محلــى مثنـل ( البنــاتى و الرومى و الغريبى و البلدى الفيومى وبز العنزة ) و اصناف عنب تصدير مثل ( ايرلى سبريور وفليم

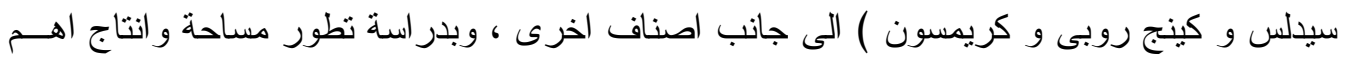

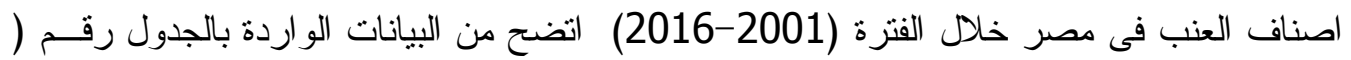
3 ) أن المساحة الكليه للعنب بلغت نحو 172489 فدان كمنوسط لفترة الدر اسة وتبين نز ايد المساحة

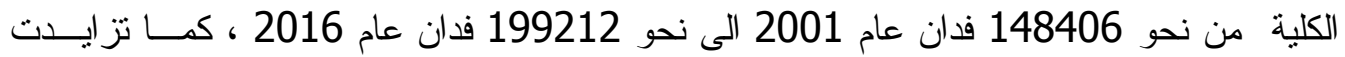
المساحة المثمرة من نحو 130694 فدان عام 2001 الى نحو 184254 فدان عام 2016 ، كمـــا

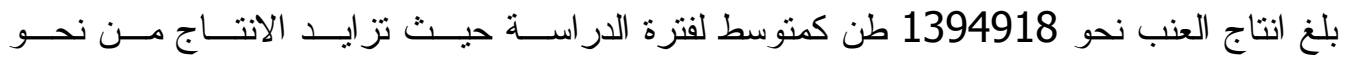
1078912 طن عام 2001 الى نحو 1691194 طن عام 2016 ، كما تنين النتائج تز ايد المساحة الكلية لاصناف عنب التصدير من نحو 3671 فدان عام 2001 الى نحو 20800 فدان عام 2016

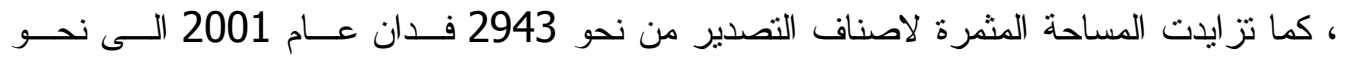

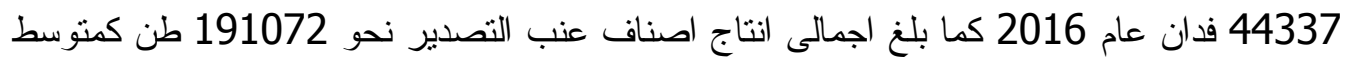

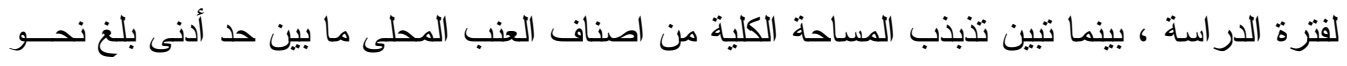

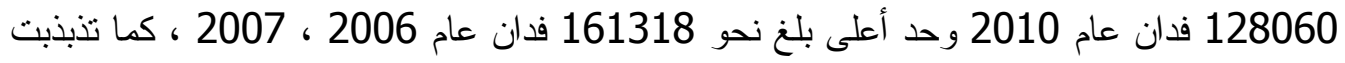

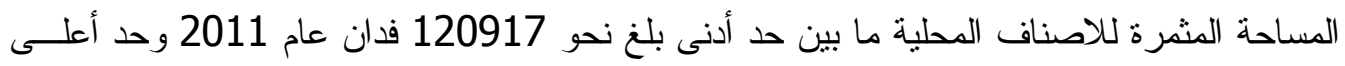

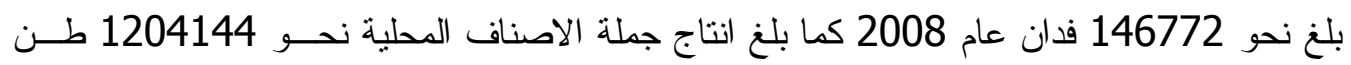

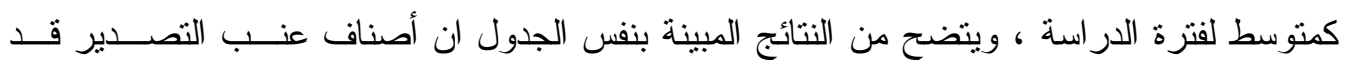
شهدت نز ايدآ ملموسا فى نسبة ما تمثلة من المساحة الكلية و المساحة المثمرة و انتاج العنب خلال فنرة 
الدر اسة فى الوقت الذى تمتل فيه جملة هـــه الاصــناف نحــ 14.5\% ، 13.3\% ، 13.7\% علـى التزتيب من اجمالى العنب كمنوسط لفترة الدراسة.

تشير نتائج معادلات الاتجاه الزمنى العام و الموضحة نتائجها بالجدول رقم ( 4 ) الى تز ايــــ

المساحة الكلية للعنب تز ايد سنوى معنوى احصائيا بلغ نحو 3294 فدان ، كمـــا تز ايــدت المســاحة الكلية لاصناف التصدير نز ايد سنوى معنوى احصائيا بلغ نحو 3784 فدان ـ كما تثبير نتائج نفس تسل الجدول الى تز ايد المساحة المثمرة للعنب تز ايد سنوى معنوى احصائيا بلغ نحو 3137 فدان ، كمـــا تبين نز ايد المساحة المثمرة لاصناف التصدير تز ايد سنوى معنوى احصائيا بلغ نحو 3323 فـــدان .

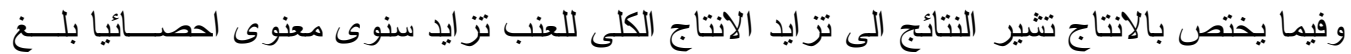

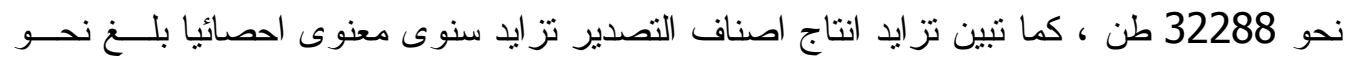

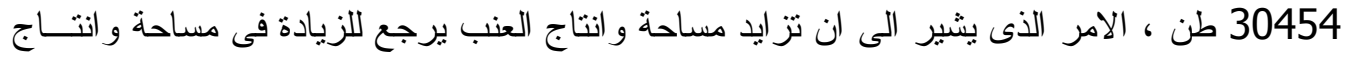
آصناف التصدير أما الاصناف المحلية فتشير النتائج الى تتاقص المساحة الكلية و المثمرة خلال فترة

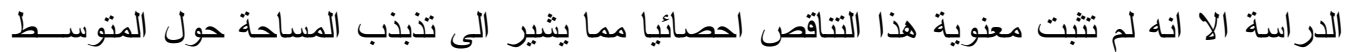
خلال فترة الدر اسة . جدول رقم (3) : تطور مساحة و انتاجية و انتاج اصناف العنب فى مصر

خلال الفترة (2016-2001)

\begin{tabular}{|c|c|c|c|c|c|c|c|c|c|c|c|c|}
\hline \multicolumn{3}{|c|}{ 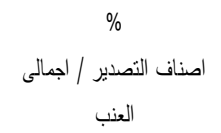 } & \multicolumn{3}{|c|}{ الجمالى للغب } & \multicolumn{3}{|c|}{ اجمالى اصنات التصدير } & \multicolumn{3}{|c|}{ اجمالى اصنان محلية } & \multirow[t]{3}{*}{ السنوات } \\
\hline |الانتاج & مسادة لماد لماد & مسادة & الانتاج & مسادة ( مساد & مسادة & الانتاج & مسادة & مسادة & الانتاج & مسادة & مسادة & \\
\hline الكلى ل الك & مثرة & كلية & الكلى الكي & 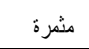 & كلية & الكىى & مثرة & كلية ل كلي & الكلى الكي & مثنرة: & كلية & \\
\hline 2.0 & 2.3 & 2.5 & 1078912 & 130694 & 148406 & 21654 & 2943 & 3671 & 1057258 & 127751 & 144735 & 2001 \\
\hline 3.5 & 2.9 & 3.6 & 1073815 & 133897 & 152488 & 37095 & 3922 & 5427 & 1036720 & 129975 & 147061 & 2002 \\
\hline 2.5 & 2.3 & 2.8 & 1196852 & 136170 & 155143 & 29712 & 3129 & 4336 & 1167140 & 133041 & 150807 & 2003 \\
\hline 2.5 & 2.3 & 2.8 & 1196852 & 136170 & 155143 & 29712 & 3129 & 4336 & 1167140 & 133041 & 150807 & 2004 \\
\hline 3.2 & 3.4 & 5.7 & 1431966 & 147270 & 165786 & 45989 & 5025 & 9408 & 1385977 & 142245 & 156378 & 2005 \\
\hline 3.4 & 3.8 & 5.6 & 1485014 & 149359 & 170940 & 50350 & 5642 & 9622 & 1434664 & 143717 & 161318 & 2006 \\
\hline 3.4 & 3.8 & 5.6 & 1485014 & 149359 & 170940 & 55125 & 5642 & 9622 & 1434664 & 143717 & 161318 & 2007 \\
\hline 4.8 & 4.7 & 6.3 & 1531418 & 153956 & 167048 & 74237 & 7184 & 10487 & 1457181 & 146772 & 156561 & 2008 \\
\hline 21.8 & 18.0 & 19.9 & 1370241 & 152282 & 167296 & 298853 & 27397 & 33362 & 1071388 & 124885 & 133934 & 2009 \\
\hline 24.5 & 20.4 & 22.0 & 1360251 & 152461 & 164105 & 333181 & 31081 & 36045 & 1027070 & 121380 & 128060 & 2010 \\
\hline 22.6 & 21.7 & 22.9 & 1320801 & 154369 & 171973 & 298581 & 33452 & 39386 & 1022220 & 120917 & 132587 & 2011 \\
\hline 21.9 & 22.0 & 22.3 & 1378815 & 157766 & 188543 & 301930 & 34656 & 41966 & 1076885 & 123110 & 146577 & 2012 \\
\hline 23.2 & 22.5 & 23.9 & 1434666 & 164310 & 192873 & 332738 & 36974 & 46083 & 1101928 & 127336 & 146790 & 2013 \\
\hline 22.5 & 22.9 & 23.7 & 1596169 & 171882 & 192934 & 359293 & 39331 & 45778 & 1236876 & 132551 & 147156 & 2014 \\
\hline 22.9 & 23.5 & 25.6 & 1686706 & 178323 & 196993 & 386555 & 41841 & 50508 & 1300151 & 136482 & 146485 & 2015 \\
\hline 23.8 & 24.1 & 24.5 & 1691194 & 184254 & 199212 & 402151 & 44337 & 48800 & 1289043 & 139917 & 150412 & 2016 \\
\hline 13.7 & 13.3 & 14.5 & 1394918 & 153283 & 172489 & 191072 & 20355 & 24927 & 1204144 & 132927 & 147562 & المتوسط \\
\hline
\end{tabular}


جدول رقم ( 4 ): معالم معادلات الاتجاه الزمنى العام لنطور مساحة و انتاجية وانتاج

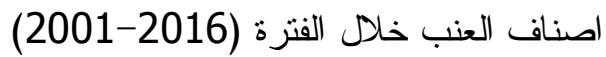

\begin{tabular}{|c|c|c|c|c|c|c|c|c|c|}
\hline \multicolumn{4}{|c|}{ اجمالى اصناف عنب التصدير } & \multirow{2}{*}{ 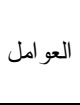 } & \multicolumn{4}{|c|}{ اجمالى اصناف العنب المحلى } & \multirow[b]{2}{*}{ 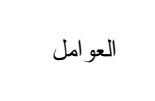 } \\
\hline $\mathrm{R}^{2}$ & $\mathrm{t}$ & $\beta$ & $\alpha$ & & $\mathrm{R}^{2}$ & $\mathrm{t}$ & $\beta$ & $\alpha$ & \\
\hline 0.90 & 11.4 & 3784 & $7241-$ & الكلية & 0.06 & $(0.94)$ & $490-$ & 151728 & المساحة الكلية \\
\hline 0.89 & 10.6 & 3323 & 7891- & المثرة & 0.01 & $(0.39)$ & $186-$ & 134508 & المساحة المثرة \\
\hline 0.86 & 9.37 & 30454 & 68088- & الانتاج & 0.003 & 0.21 & 1834 & 1188555 & الانتاج \\
\hline \multicolumn{9}{|c|}{ اجمالى العنب } & \multirow{2}{*}{ 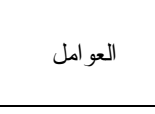 } \\
\hline \multicolumn{3}{|c|}{$R^{2}$} & \multicolumn{2}{|c|}{$\mathrm{t}$} & \multicolumn{2}{|c|}{$\beta$} & \multicolumn{2}{|c|}{$\alpha$} & \\
\hline \multicolumn{3}{|c|}{0.89} & \multicolumn{2}{|c|}{10.4} & \multicolumn{2}{|c|}{3294} & \multicolumn{2}{|c|}{144487} & المساحة الكلية \\
\hline \multicolumn{3}{|c|}{0.93} & \multicolumn{2}{|c|}{13.2} & \multicolumn{2}{|c|}{3137} & \multicolumn{2}{|c|}{126618} & المساحة المثرة \\
\hline \multicolumn{3}{|c|}{0.66} & \multicolumn{2}{|c|}{5.2} & \multicolumn{2}{|c|}{32288} & \multicolumn{2}{|c|}{1120467} & الانتاج \\
\hline
\end{tabular}

.16

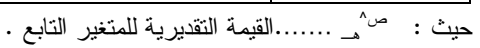

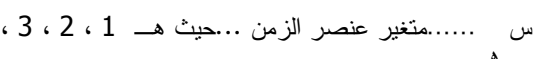

المصدر :جمعت وحسبت من بيانات الجدول رقم ( 3 ) .

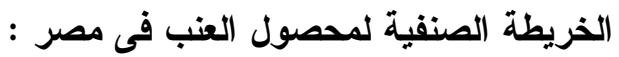

باستعراض نطور أهم اصناف العنب فى مصر خلال السنوات الاخيرة تنين النتائج الموضحة بالجدول رقم ( 5 ) التغير فى الخريطة الصنفية للعنب فى مصر خلال الفترنين (2001-

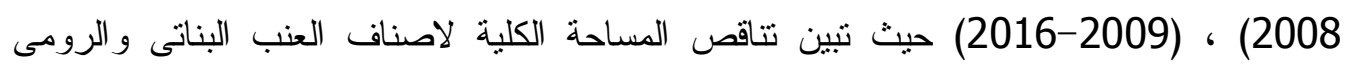

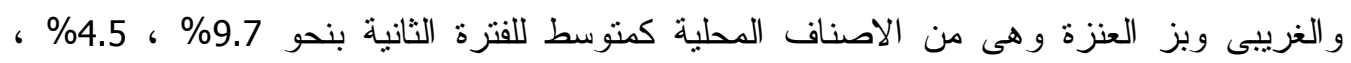
17.8\% ، 23.1\% على الترتيب مقارنة بما كانت علية خلال الفترة الاولى وقد ثنتت معنوية الفرق بين المتوسطين ، كما تبين تز ايد متوسط مساحة اصناف العنب ايرلى سبريور وفليم سيدلس و الكينج

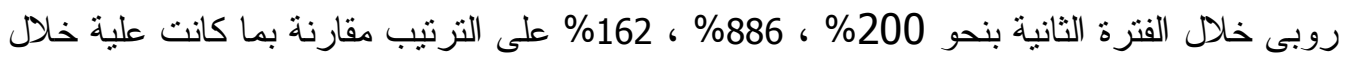
الفترة الاولى وقد ثبتت معنوية الفرق بين المتوسطين. وبصفة عامة تنين تزايد المساحة الكلية

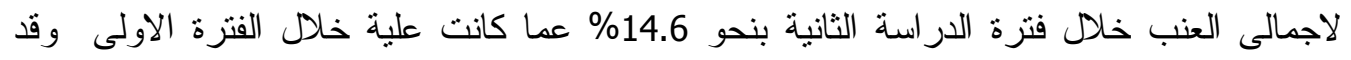
ثنتت معنوية الفرق بين المتوسطين وهو ما يعود للزيادة المعنوية فى المساحة الكلية لاجمالى آصناف

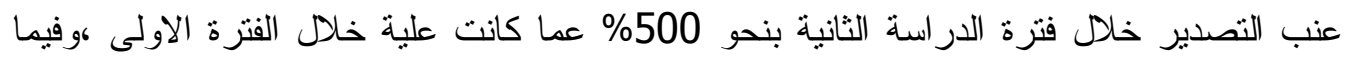
يتعلق بالمساحة الكلية لاجمالى أصناف العنب المحلى فقد تبين تتاقصها خلال فترة الدراسة الثانية

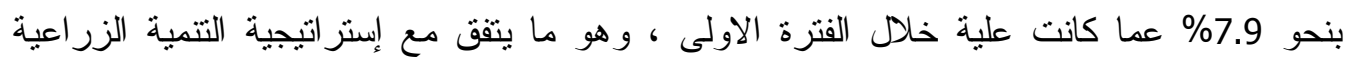

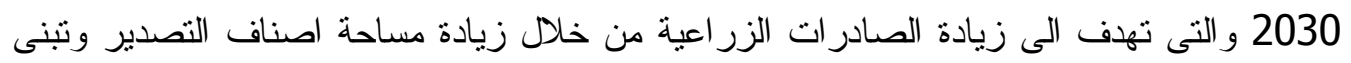


جدول رقم ( 5 ): تغير المساحة الكلية لاصناف العنب فى مصر خلال الفترة (2016-2001)

\begin{tabular}{|c|c|c|c|c|}
\hline \multirow{2}{*}{ 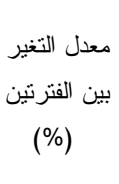 } & \multirow{2}{*}{ "t" قيمة } & \multicolumn{2}{|c|}{ متوسط المساحة الكلية } & \multirow{2}{*}{ الاصناف } \\
\hline & & منوسط الفترة الثانية & $\begin{array}{l}\text { (2001-2008 منوسط الفترة الاولى } \\
\text { (2008) }\end{array}$ & \\
\hline $9.7-$ & $(* * 3.8)$ & 92874 & 102833 & بنانى \\
\hline $4.5^{-}$ & $(* 2.29)$ & 41904 & 43878 & رومى \\
\hline-17.8 & $(* * 6.62)$ & 1076 & 1310 & غريبى \\
\hline 12.5 & $* * 5.63$ & 2649 & 2354 & بلدى فيومى \\
\hline $23.1-$ & $(* 2.34)$ & 2491 & 3239 & بز العنزة \\
\hline 7.9- & $(* * 4.12)$ & 141500 & 153623 & جملة الاصناف المحلية \\
\hline 200 & $* * 8.85$ & 7418 & 2471 & ايرلى اسبريو \\
\hline 886 & $* * 21.9$ & 29218 & 2963 & فليم سيدلس \\
\hline 162 & $* * 11.46$ & 4402 & 1679 & كينج روبى \\
\hline 500 & $* * 18.85$ & 42741 & 7114 & جملة أصناف التصدير \\
\hline 14.6 & $* * 5.04$ & 184241 & 160737 & جملة العنب \\
\hline
\end{tabular}

المصدر : جمعت وحسبت من بيانات الجدول رقم( 3 ).

صادرات العنب الطازج المصرى :

بدر اسة نطور كمية وقيمة الصـادرات المصرية من محصول العنب خلال فتـرة الدراســـة

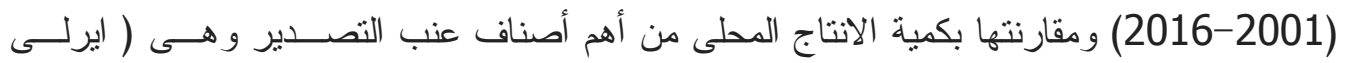

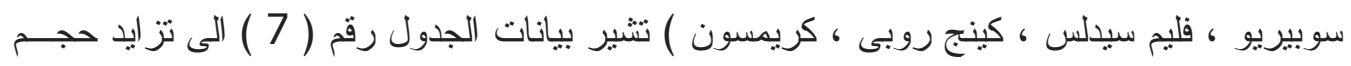

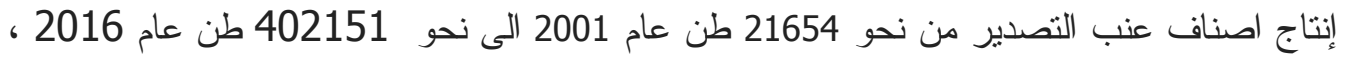

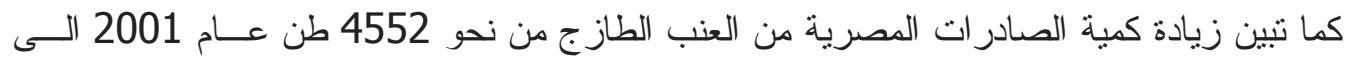

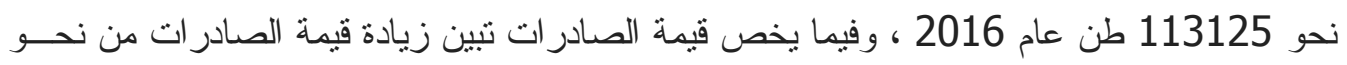
1294 الف دولار عام 2001 الى نحو 212761 الف دولار عام 2016 ، كما تشير نتائج نفـس فئس

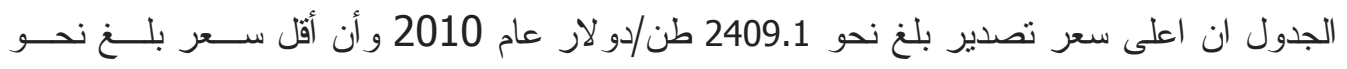

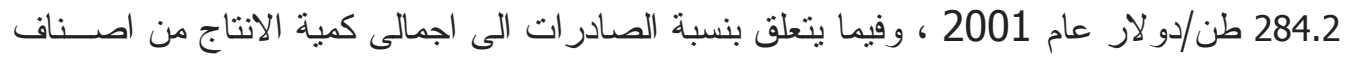

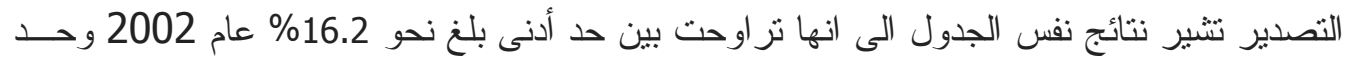

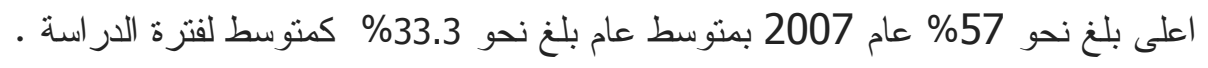

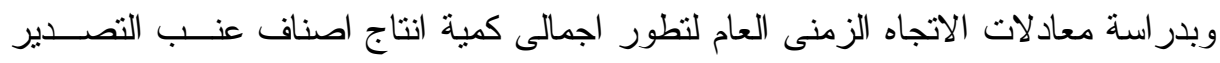

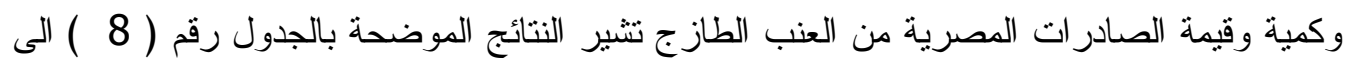

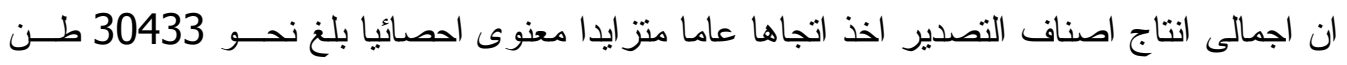

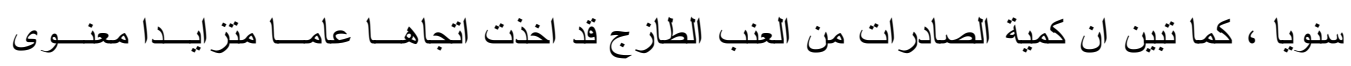

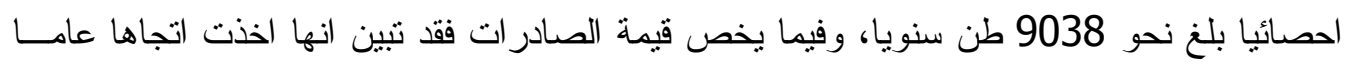

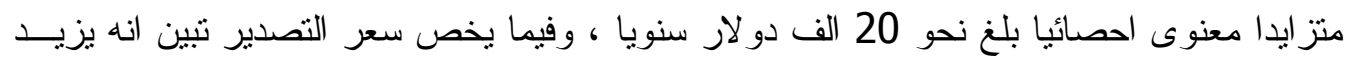

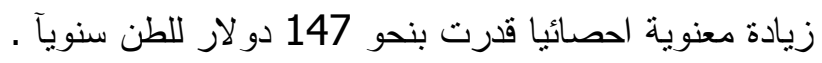


جدول رقم ( 7 ) : نطور اجمالى انتاج اصناف عنب التصدير وكمية وقيمة

صادر ات العنب الطازج المصرى خلال الفترة (2016-2001)

\begin{tabular}{|c|c|c|c|c|c|}
\hline 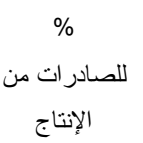 & سعر التصدير & 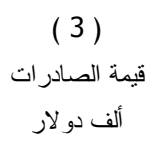 & كمية الصادر ات 2 ( ) & $\begin{array}{c}\text { الإنتاج" } \\
\text { ( } 1 \text { ( } \\
\text { طن }\end{array}$ & السنوات \\
\hline 21.0 & 284.2 & 1294 & 4552 & 21654 & 2001 \\
\hline 16.2 & 303.2 & 1817 & 5993 & 37095 & 2002 \\
\hline 25.0 & 395.1 & 2930 & 7416 & 29712 & 2003 \\
\hline 48.5 & 740.8 & 10684 & 14423 & 29712 & 2004 \\
\hline 53.5 & 684.4 & 16837 & 24602 & 45989 & 2005 \\
\hline 55.2 & 786.0 & 21859 & 27810 & 50350 & 2006 \\
\hline 57.0 & 786.0 & 24710 & 31436 & 55125 & 2007 \\
\hline 47.9 & 786.0 & 27931 & 35535 & 74237 & 2008 \\
\hline 45.4 & 1662.2 & 225377 & 135586 & 298853 & 2009 \\
\hline 25.2 & 2409.1 & 202052 & 83872 & 333181 & 2010 \\
\hline 33.5 & 2132.6 & 213179 & 99963 & 298581 & 2011 \\
\hline 38.4 & 1932.8 & 224306 & 116054 & 301930 & 2012 \\
\hline 26.5 & 2080.2 & 183355 & 88144 & 332738 & 2013 \\
\hline 31.6 & 2159.6 & 245080 & 113485 & 359293 & 2014 \\
\hline 30.0 & 2095.5 & 242897 & 115911 & 386555 & 2015 \\
\hline 28.1 & 1880.8 & 212761 & 113125 & 402151 & 2016 \\
\hline 33.3 & 1319.9 & 116067 & 63619 & 191072 & المتوسط \\
\hline
\end{tabular}

" إنتاج أصناف عنب التصدير ايرلى سوبريو ، فيلام سيدلس ، كنج روبى ، كريمسون.

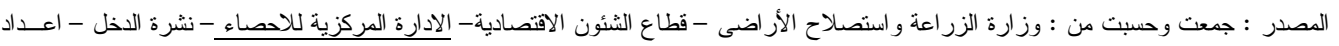

(2),(3):source: United Nations, UN Comtrade Database.

مما يشير الى ان انتاج اصناف التصدير يزيد بنسبة اكبر من زيادة كمية الصادرات خــلال فترة الدراسة اى انه لابد من بذل المزيد من الجهد للتوسع فى الصادر ات المصرية من العنــب مــن

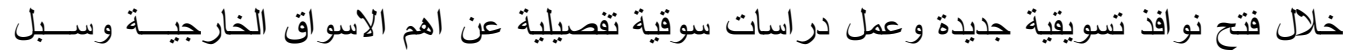
تحسين تتافسية صادر ات العنب المصرى بها. جدول رقم ( 8 ) : معادلات الاتجاه الزمنى العام لتطور اجمالى كمية انتاج اصناف التصدير وكمية

وقيمة الصادر ات المصرية من محصول العنب الطازج خلال الفترة (2001-2016 )

\begin{tabular}{|c|c|c|c|c|}
\hline $\mathrm{R}^{2}$ & $\mathrm{t}$ & $\beta$ & $\alpha$ & 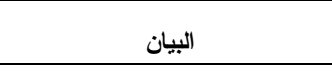 \\
\hline 0.86 & 9.45 & 30433 & $67610-$ & اجمالى انتاج اصناف التصدير (طن) \\
\hline 0.79 & 7.36 & 9038 & $13207-$ & كمية الصادر ات (طن) \\
\hline 0.79 & 7.43 & 20091 & 54709- & قيمة الصادر ات (الف دولار) \\
\hline 0.81 & 7.66 & 147 & 70.8 & سعر التصدير (طن/دولار) \\
\hline
\end{tabular}


أستقرار الصادرات المصرية من العنب :

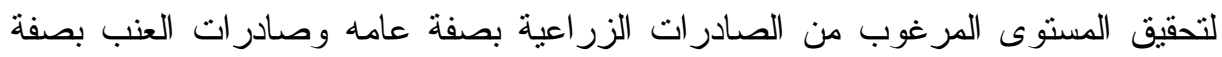

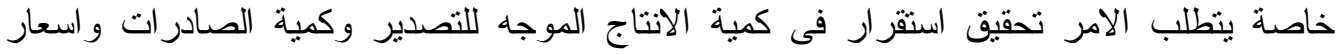

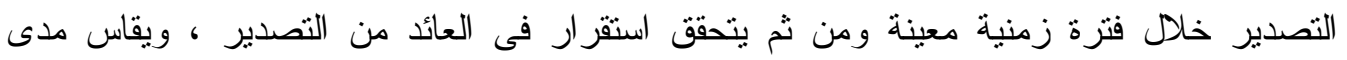

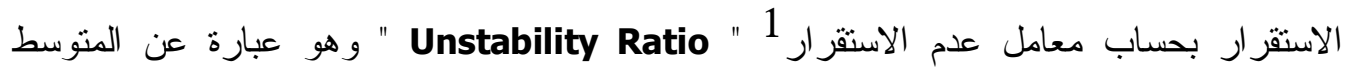

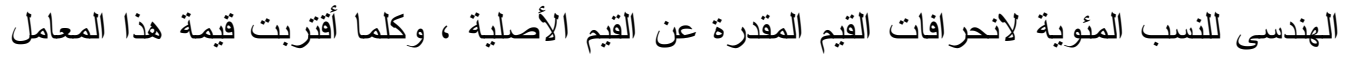

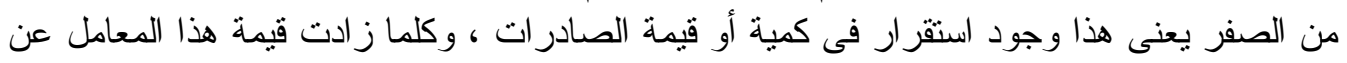

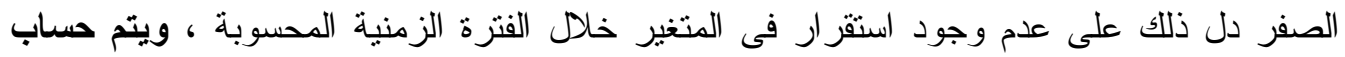
معامل علم الاستقرار كما يلى : ملى :

$100 \times$

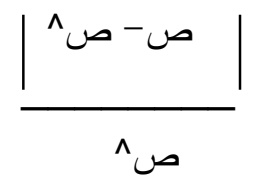

$$
\text { معامل عدم الاستقرار }
$$

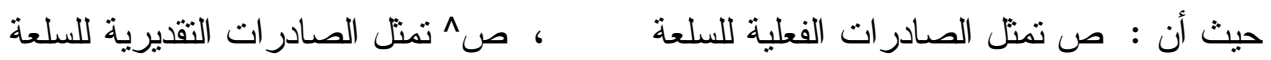
تنتير بيانات الجدول رقم ( 9 ) الى تطور معاملات عدم الاستقرار لكل من كميـــة إنتــاج

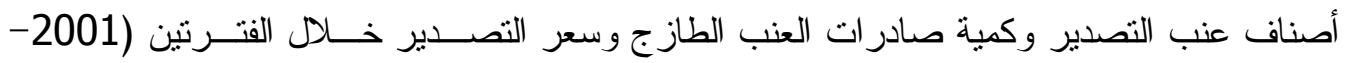

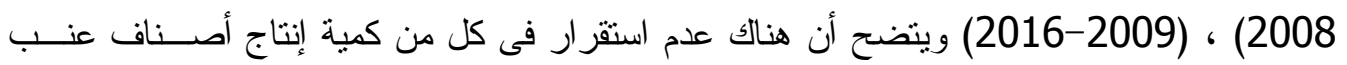

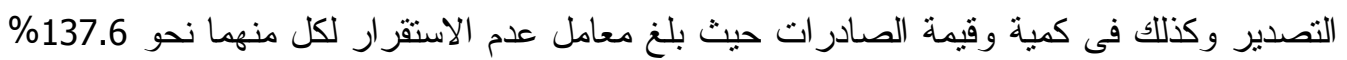

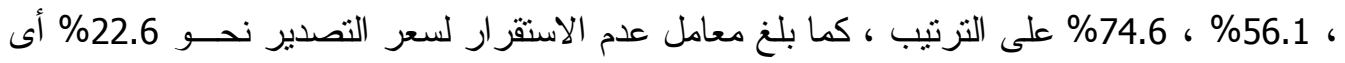

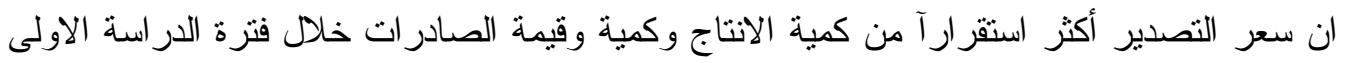

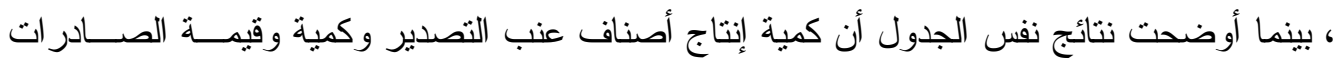

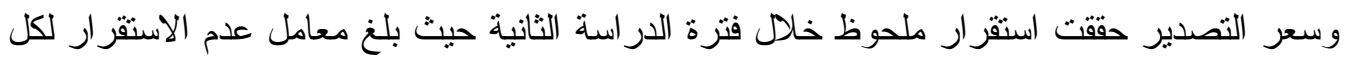

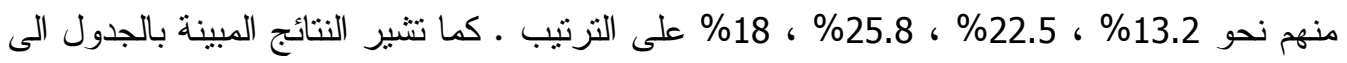

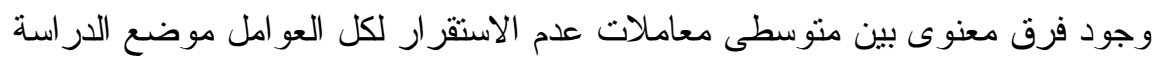
جدول رقم (9 ) : معاملات عدم الاسنقر ار لمحصول العنب الطازج خلال الفترة (2016-2001)

\begin{tabular}{|c|c|c|c|c|}
\hline \multicolumn{4}{|c|}{ معاملات عدم الاستقر ار } & \multirow{2}{*}{ 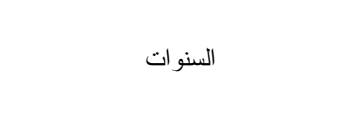 } \\
\hline سعر التصدير & قيمة الصادر ات & كمية الصادر ات & كمية إنتاج أصناف التصدير & \\
\hline 22.6 & 74.6 & 56.1 & 137.6 & متوسط الفترة الاولى(2008-2001) \\
\hline 18.0 & 25.8 & 22.5 & 13.2 & متوسط الفترة الثانية(2016-2009) \\
\hline$* * 20.2-$ & $* * 65.4-$ & $* * 59.8-$ & $* * 90.4-$ & معنوية الفرق بين المتوسطين \\
\hline
\end{tabular}
المصدر : جمعت وحسبت من : (1): وزارة الزر اعة واستصلاح الاراضى ، قطاع الثئون الاقتصادية، الادارة العامه للاحصاء، نشرة الاقتصاد الزر اعى ، اعداد متفرقة.

(2): Source:United Nations, UN Comtrade Database.

$$
1 \text { يتم التعبير عن معامل عدم الاستقرار بغض النظر عن الإشارة . Advantage }
$$

2 Dr. Memedovic , O. , " On The Theory and Measurment of Comparative Advantage" - An Empirical Analysis of Yugoslav Trade In Manufactures With The OECD Countries , 1970 1986 “, Thesis Publishers, Amsterdam , 1994. 
ويشير ذلك الى اتجاه العو امل موضع الدر اسة للاسنقرار خلال الفترة الثانية عن ما كانــــ علية خلال الفترة الاولى • و هو ما قد يعزى الى ان اتباع الدولة لسياسات زر اعية تهــف لتحسـين الصادر ات وزيادة مساحات اصناف التصدير مما ترتب عليه زيادة فى الاستقرار لكمية الانتاج وكمية

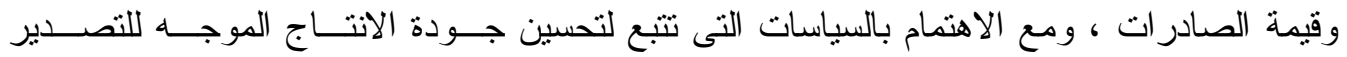
و الاهتمام بالمو اصفات و المو اعيد المناسبة لكسب الاسو اق الخارجية سوف تزيد كمية الصادرات مسن العنب المصرى خاصة لاسو اق الاتحاد الاوروبى التى تسمح بدخول كميات غير محدده من العنــب المصرى معفاه من الجمارك خلال الفترة من (14/1-7/2) . صادرات العنب الطازج المصرى فى السوق العالمى: تبلغ اجمالى الصادر ات العالمية من محصول العنب الطازج نحو 4333 الف طن كمتوسط للفترة (2014-2016) وتبلغ قيمتها نحو 7982 مليون دو لار وهو ما توضحه بيانات الجدول رقم (10)، وتعد مصر احد اهم الدول المصدرة للعنب الطازج على مستوى العالم حيث تحتل المرتبة الثالثة عشرة بكمبة صادرات بلغت نحو 114الف طن تمنل نحو 2.6\% من اجمالى الصادرات العالمية كمتوسط لنفس الفترة ، كما تعتبر شيلى وايطاليا وامريكا وجنوب افريقيا اهم الدول المصدرة للعنب باهمية نسبية قدرت بنحو 16.9\%، 10.8\% ، 9.4 \% \% 7.5 \% جدول رقم ( 10 ) ): الاهمية النسبية لكمية الصادر ات المصرية من العنب الطازج مقارنة باهم الدول المصدرة على مستوى العالم كمنوسط للفتزة (2016-2014)

\begin{tabular}{|c|c|c|c|c|}
\hline$\%$ & قيمة الصادر ات (الف دو لار ) & $\%$ & كمية الصادر ات (طن) & اهم المصدرين \\
\hline 17.8 & 1418292 & 16.9 & 730217 & 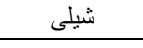 \\
\hline 9.3 & 739590 & 10.8 & 467703 & ايطاليا \\
\hline 11.9 & 951727 & 9.4 & 407992 & امريكا \\
\hline 6.3 & 500911 & 7.5 & 324258 & جنوب افريقيا \\
\hline 8.4 & 670260 & 6.7 & 292067 & بيرو بير \\
\hline 9.2 & 731383 & 6.6 & 285047 & هولندا \\
\hline 1.9 & 149275 & 4.7 & 202050 & تركيا \\
\hline 7.5 & 594767 & 4.5 & 196121 & الصين \\
\hline 4.3 & 339574 & 4.0 & 174981 & هونج كونج \\
\hline 2.0 & 158125 & 3.6 & 157244 & المكسبك \\
\hline 4.2 & 333208 & 3.5 & 150535 & اسبانيا \\
\hline 2.4 & 188801 & 2.8 & 119806 & 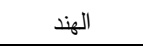 \\
\hline 2.9 & 233579 & 2.6 & 114174 & مصر \\
\hline 12.2 & 972960 & 16.4 & 710896 & 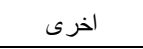 \\
\hline 100.0 & 7982453 & 100.0 & 4333092 & العالم الم \\
\hline
\end{tabular}

source: United Nations, UN Comtrade Database.

\section{التوزيع الجغر افى لصادرات مصر من العنب الطازج :}

تتعدد وتتباين الأسواق العالمية التى يتم تصدير العنب إليها وكذلك تخنلف الكميات المصدرة

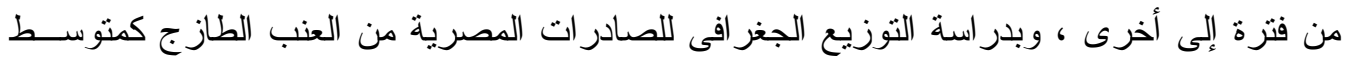


للفترة (2014-2016) و الموضح نتائجها بالجدول رقم (11) يتبين أن متوسط الكمية المصدرة مسـن

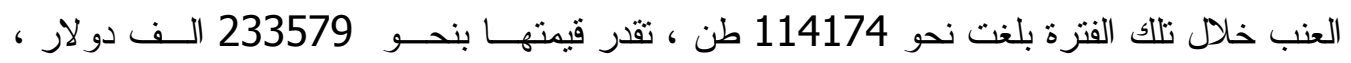

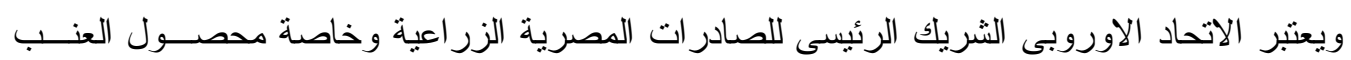

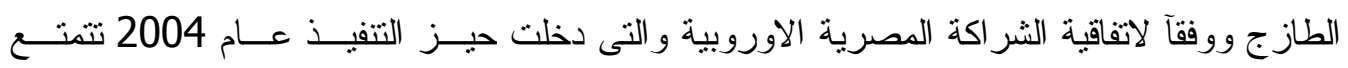

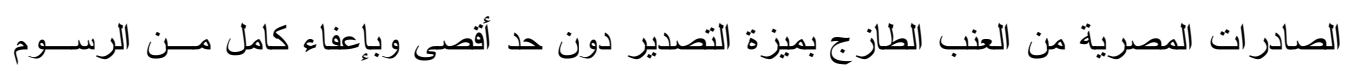

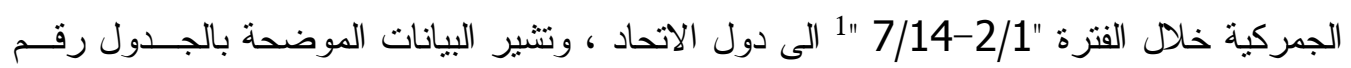

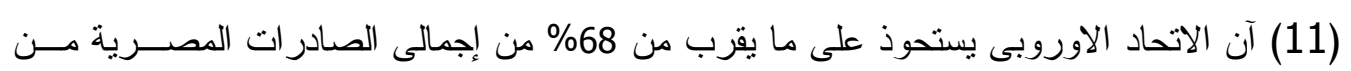

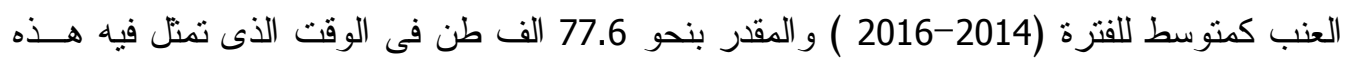
الكمية نحو 4.8\% من اجمالى واردات الاتحاد الاوروبى من العنب الطازج و المقدرة بنحــو 1606 الف طن كمتوسط لنفس الفترة. جدول رقم (11) : الاهمية النسبية لصادر ات مصر من العنب الطازج من اجمالى لفئ

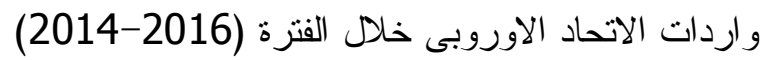

\begin{tabular}{|c|c|c|c|c|c|}
\hline$\%$ & كمية واردات الاتحاد الاوروبى من العالم & $\%$ & كمية الصادر ات المصرية & $\begin{array}{c}\text { كمية الصادر ات المصرية للاتحاد } \\
\text { الاوروبى (طن) }\end{array}$ & السنوات \\
\hline 4.4 & 1580784 & 61.2 & 113485 & 69450 & 2014 \\
\hline 5.1 & 1609157 & 70.9 & 115911 & 82154 & 2015 \\
\hline 5.0 & 1626841 & 71.8 & 113125 & 81215 & 2016 \\
\hline 4.8 & 1605594 & 68.0 & 114174 & 77606 & المتوسط \\
\hline
\end{tabular}

Source: United Nations, UN Comtrade Database.

وفيما يخص أهم الدول المستوردة للعنب الطازج المصرى نتثير البيانات الموضحة بالجدول

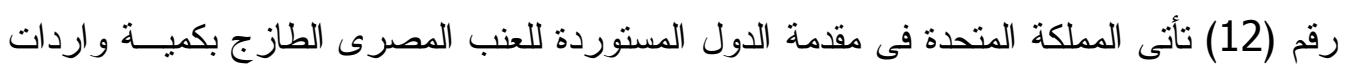

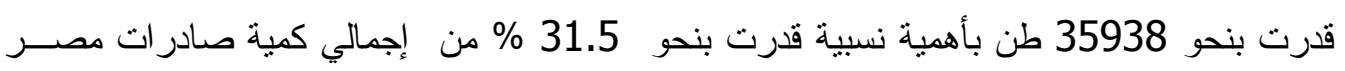

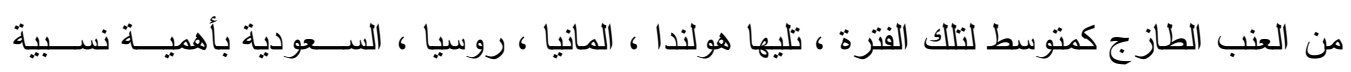

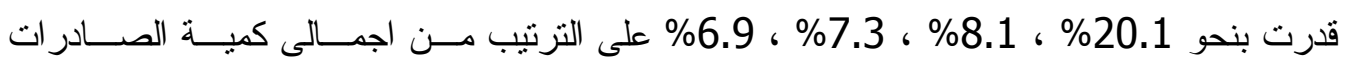
المصرية من العنب الطازج خلال تلك الفترة. جدول رقم ( 12): التوزيع الجغر افى لصادرات العنب المصرى الطازج

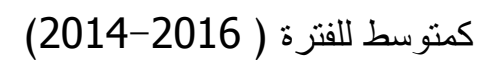

\begin{tabular}{|c|c|c|c|}
\hline (\%) من اجمالى كمية الصادر ات & قيمة الصادرات & كمية الصادر ات & اهم الدول المستوردة \\
\hline 31.5 & 76707 & 35938 & المملكة المتحدة \\
\hline 20.1 & 49596 & 22916 & هولندا \\
\hline 8.1 & 21018 & 9223 & 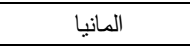 \\
\hline 7.3 & 16249 & 8390 & روسيا الاتحادية \\
\hline 6.9 & 8912 & 7827 & 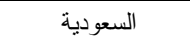 \\
\hline 26.2 & 61097 & 29880 & اخرى \\
\hline 100.0 & 233579 & 114174 & الاجمالى \\
\hline
\end{tabular}

source: United Nations, UN Comtrade Database.

1 سعد زكى نصار ( دكتور) ، الملف الزراعى فى إتفاق المشاركة المصرية الأوروبية ، الجمعية المصرية للاقتصاد الزراعى ، 2005 . 


\section{موسمية الصادرات المصرية من العنب الطازج:}

يتسم الأنتاج الزر اعى عموما بالموسمية وتختلف الدول فى ميز اتها التتافسية داخل الاسواق

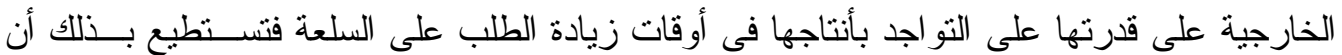
تكسب نصيب سوقى وسعر أفضل داخل الاسو اق الخارجية ـ ويبدأ موسم انتاج العنب فى مصر فـى شهر مايو ويستمر حتى سبتمبر وتتشير بيانات الجدول رقم (13) أن ذروة موســم تصــدير العنــب المصرى ييدأ فى شهر مايو بأهمية نسبية تبلغ 21.5\% من اجمالى صـادرات العنب و البالغــة نحــو 114174 طن كمنوسط للفترة (2014-2016) وهى الاصناف المبكرة ، ثم يتركز نحــ 56.1\% من اجمالى الصادر ات فى شهر يونية لتعود للانخفاض التدريجى مرة اخــرى فـى شــــرى يوليــو و اغسطس باهمية نسبية قدرت بنحو 14.4\% ، 3.8\% على النزتيب . جدول رقم (13) : موسمية الصادرات المصرية من العنب الطازج كمتوسط للفترة (2016-2014)

\begin{tabular}{|c|c|c|c|c|c|c|c|c|}
\hline \multicolumn{2}{|c|}{ واردات المانيا } & \multicolumn{2}{|c|}{ و اردات هو لندا } & \multicolumn{2}{|c|}{ و اردات انجلتز ا } & \multicolumn{2}{|r|}{ صادر ات مصر } & \multirow{2}{*}{ شهور السنة } \\
\hline$\%$ & الكمية (طن) & $\%$ & الكمية (طن) & $\%$ & الكمية (طن) & $\%$ & الكمية (طن) & \\
\hline 5.0 & 16184 & 13.3 & 47194 & 9.3 & 24499 & 0.3 & 340 & يناير \\
\hline 5.1 & 16520 & 11.7 & 41673 & 7.6 & 20164 & 0.5 & 557 & فبر اير \\
\hline 6.0 & 19416 & 15.7 & 55885 & 10.4 & 27399 & 0.5 & 595 & مارس \\
\hline 6.1 & 19598 & 15.6 & 55476 & 9.9 & 26076 & 0.5 & 527 & أبريل \\
\hline 6.1 & 19573 & 11.4 & 40592 & 7.8 & 20664 & 21.4 & 24487 & مايو \\
\hline 5.7 & 18240 & 5.8 & 20589 & 8.4 & 22264 & 56.1 & 64042 & يونيه \\
\hline 6.1 & 19673 & 2.0 & 7203 & 5.0 & 13209 & 14.4 & 16489 & يوليه \\
\hline 11.9 & 38255 & 1.8 & 6360 & 5.5 & 14381 & 3.8 & 4382 & أغسطس \\
\hline 14.8 & 47420 & 2.3 & 8060 & 7.5 & 19729 & 0.9 & 1045 & سبتمبر \\
\hline 16.7 & 53701 & 3.1 & 11013 & 9.3 & 24495 & 0.7 & 782 & أكتوبر \\
\hline 9.8 & 31633 & 5.6 & 19839 & 9.2 & 24297 & 0.5 & 519 & نوفمبر \\
\hline 6.6 & 21162 & 11.8 & 42034 & 10.1 & 26656 & 0.4 & 410 & ديسمبر \\
\hline 100.0 & 321375 & 100.0 & 355919 & 100.0 & 263833 & 100.0 & 114174 & الإجمالى \\
\hline
\end{tabular}

Sources: ITC calculations based on UN COMTRADE statistics.

من ناحية أخرى تتشير نتائج نفس الجدول الى موسمية واردات أهم الاســـواق الاســتير ادية للعنب الطازج المصرى وقد تم التركيز على اسواق انجلتر اوهولندا باعتبار هما اهم الدول المستوردة ولته

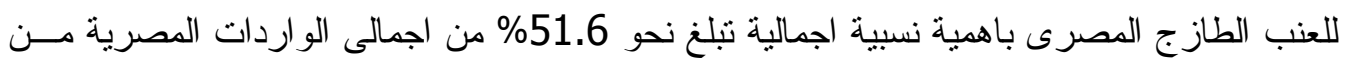

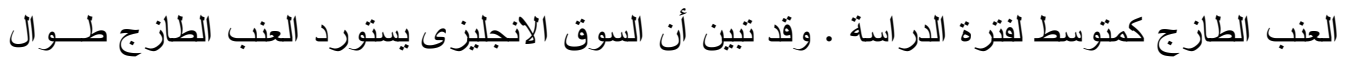
العام تزيد الكمبات فى شهور نوفمبر وديسمبر ويناير ومارس وابريل وتكون اقل فى شهور تصــدير

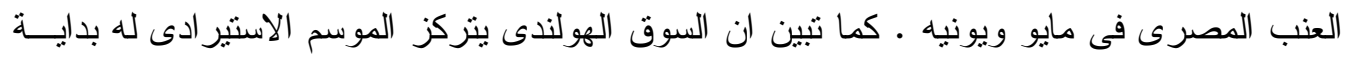

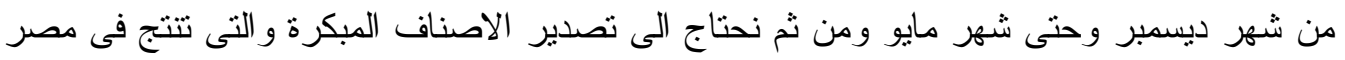

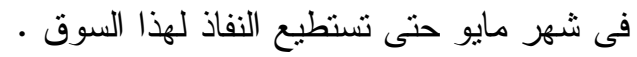

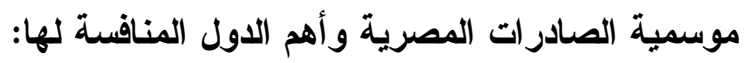
لكى تكون الدولة منافسة يجب ان تتفق فى نفس موسم التصدير أى تكون صادر اتها فى لهى 
نفس شهور تصدير الدولة المقارن بها ، وتوضح النتائج الموضحة بالجدول رقم (14) مقارنة بين اهم شهور تصدير العنب المصرى الطازج وشهور تصدير اهم الدول المنافسة لها وهى شيلى وجنوب افريقيا والهند مع استبعاد الدول المنافسة من داخل الاتحاد الاوروبى لما تتتنع به من مزايا لكونها عضو ا فى الاتحاد الاوروبى. جدول رقم (14) : موسمية الصادر ات المصرية و أهم الدول المنافسة لها من العنب الطاز ج كمتوسط للفترة (2016-2014)

\begin{tabular}{|c|c|c|c|c|c|c|c|c|c|c|}
\hline$\%$ & صبية & $\%$ & صادر شية & $\%$ & كنوب & $\%$ & صادر ات كمية & $\%$ & الصمادر ات & الشهور \\
\hline 27.5 & 76401 & 2.8 & 22519 & 21.5 & 63334 & 2.3 & 2628 & 0.3 & 340 & يناير \\
\hline 20.5 & 56929 & 9.4 & 77030 & 25.8 & 75815 & 9.7 & 11290 & 0.5 & 557 & فبر اير \\
\hline 12.8 & 35432 & 15.2 & 124330 & 25.1 & 73941 & 28.6 & 33330 & 0.5 & 595 & مارس \\
\hline 4.1 & 11318 & 26.3 & 214671 & 17.7 & 52030 & 38.7 & 45123 & 0.5 & 527 & ابريل \\
\hline 0.5 & 1395 & 31.4 & 256873 & 4.7 & 13688 & 17.8 & 20731 & 21.4 & 24487 & مايو \\
\hline 0.2 & 543 & 12.8 & 104750 & 0.6 & 1718 & 0.9 & 1055 & 56.1 & 64042 & يونية \\
\hline 0.1 & 357 & 1.6 & 13308 & 0.1 & 272 & 0.1 & 64 & 14.4 & 16489 & يوليو \\
\hline 0.1 & 368 & 0.4 & 3192 & 0.1 & 295 & 0.0 & 17 & 3.8 & 4382 & اغسطس \\
\hline 0.4 & 1019 & 0.0 & 264 & 0.1 & 287 & 0.0 & 33 & 0.9 & 1045 & سبتمبر \\
\hline 1.3 & 3566 & 0.0 & 4 & 0.1 & 311 & 0.0 & 28 & 0.7 & 782 & اكتوبر \\
\hline 9.4 & 26200 & 0.0 & 0 & 0.1 & 352 & 0.2 & 195 & 0.5 & 519 & نوفمبر \\
\hline 23.0 & 63892 & 0.0 & 58 & 4.2 & 12255 & 1.7 & 1956 & 0.4 & 410 & ديسمبر \\
\hline 100.0 & 277420 & 100.0 & 816998 & 100.0 & 294297 & 100.0 & 116451 & 100.0 & 114174 & الاجمالى \\
\hline
\end{tabular}

Sources: ITC calculations based on UN COMTRADE statistics.

وقد أظهرت النتائج أن شيلى تتصدر قائمة المصدرين للعنب الطازج بكمية صادرات بلغت

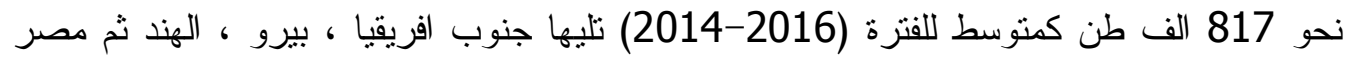

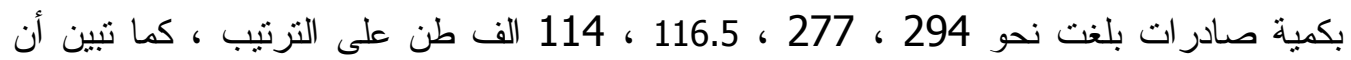
جنوب افريقيا و الهند يبدأ الموسم التصديرى لهما من ديسمبر ويستمر حتى مايو أما بيرو فيبدأ الموسم

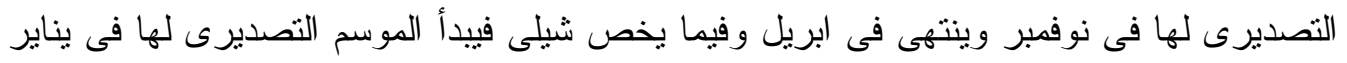

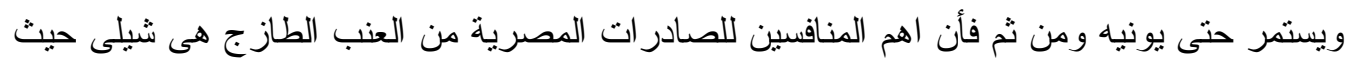

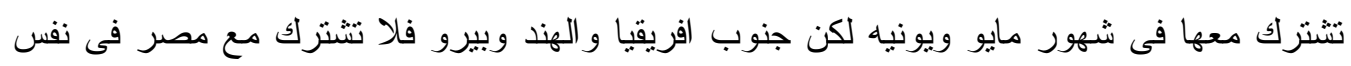

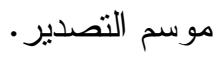

\section{مؤشرات الأداء التصديرى للعنب الطازج المصرى فى أهم أسواقة الخارجية:}

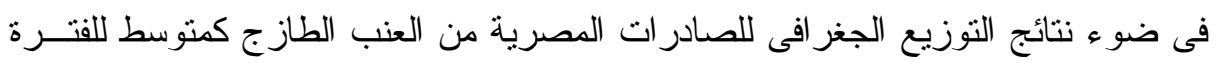

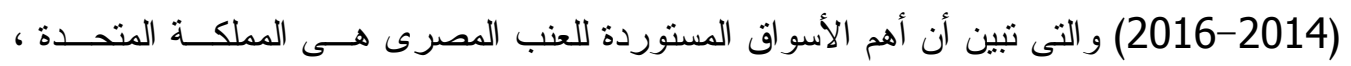

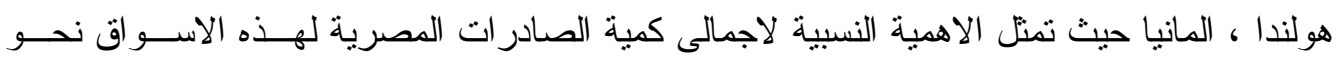

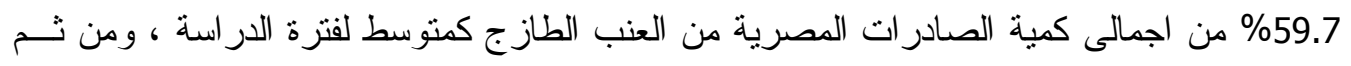

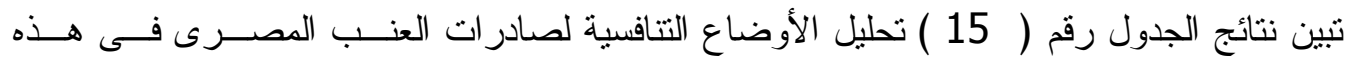
الاسو اق من حيث مؤشر التنافسية السعرية ومعدل الاختر اق 
1 - 1 سوق المملكة المتحدة

توضح بيانات الجدول رقم ( 15 ) أن إجمالى واردات المملكة المتحدة من العنب كمنوســـ للفتـرة

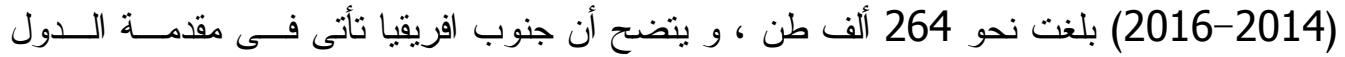
المصدرة للعنب الطاز ج إلى المملكة المتحدة بأهمية نسبية بلغت نحو 23.7\% يليها كل من أسـبانيا ، شيلى ، مصر ، اليونان ثم الهند بأهمية نسبية بلغت نحسـ 15.4\% ، 13.3\% ، 8\% ، 5.5\% على الترتيب كمتوسط لنفس الفترة ـ وبتقدير المتوسط المرجح لسعر تصدير الطن بين أهم الدول المصدرة للعنب إلى سوق المملكة المتحدة كمتوسط للفترة (2016-2014) نبين أنه قدر بنحو 2643 دو لار ، كما قدر مؤشر النتافسية السعرية لسعر تصدير العنب المصرى فى سوق المملكة المتحدة بنحو 0.30

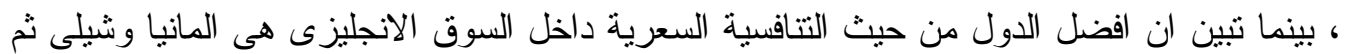
جنوب افريقيا بنحو صفر ، 0.17 ، 0.28 على التزتيب. الأمر الذى يشير إلى أن مؤشـر التتافسـية السعرية للعنب المصرى فى سوق المملكة المتحدة فى وضع جيد الا انه يو اجه بمنافسة مــن عنــب إبـ شيلى وجنوب افريقيا ذات الأفضلية النسبية فى السعر، فى حين ان النتافسية السعرية للعنب المصرى فى وضع أفضل من الهند و هولندا و اسبانيا و اليونان. وفيما يتعلق بمؤشر معدل اختراق السوق فقد أوضحت النتائج المبينة بالجدول رقم (15) أن معدل اختراق محصول العنب المصرى الطازج الى سوق المملكة المتحدة بلغ نحو 0.088 كمتوسط

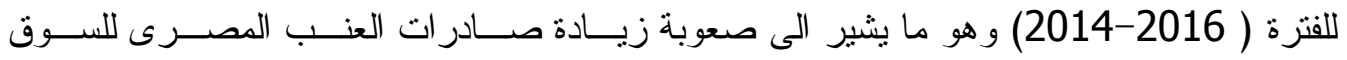
الاتجليزى نتيجة لضيق السوق وصعوبة اختر اقة. جدول رقم ( 15 ): النصيب السوقى والأهمية النسبية لسعر تصدير العنب المصرى بأهم أسو اقه التصديرية كمتوسط للفترة ( 2016-2014)

\begin{tabular}{|c|c|c|c|c|c|c|}
\hline${ }^{R} A_{j}$ & $\mathrm{P}_{\mathrm{Aj}}$ & متوسط السعر & الحصة السوقية داخل & من الدولة (طن) & الدولة المصدرة & أهم الأسو اق \\
\hline 0.28 & 0.95 & 2523 & 23.7 & 62368 & جنوب افريقيا & \multirow{9}{*}{ المملكة المتحدة } \\
\hline 0.46 & 1.04 & 2753 & 15.4 & 40659 & اسبانيا & \\
\hline 0.17 & 0.90 & 2381 & 13.3 & 35075 & شيلى & \\
\hline 0.30 & 0.96 & 2546 & 8.0 & 21165 & مصر & \\
\hline 1.00 & 1.30 & 3434 & 5.5 & 14463 & اليونان & \\
\hline 0.41 & 1.02 & 2689 & 5.5 & 14609 & الهند & \\
\hline 0.00 & 0.82 & 2168 & 4.8 & 12651 & 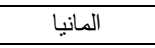 & \\
\hline \multirow[t]{3}{*}{0.44} & 1.03 & 2723 & 4.5 & 11820 & هو الندا & \\
\hline & -- & -- & 19.3 & 50,848 & دول أخرى & \\
\hline & \multicolumn{2}{|c|}{$\frac{1}{2643}$} & \multicolumn{2}{|c|}{263657} & \multicolumn{2}{|c|}{ اجمالى واردات المملكة المتحدة } \\
\hline \multicolumn{5}{|c|}{0.088} & \multicolumn{2}{|c|}{ معدل اختراق سوق المملكة المتحدة } \\
\hline 0.52 & 1.05 & 2623 & 33.1 & 116076 & جنوب افريقيا & \multirow{8}{*}{ هولندا } \\
\hline 1.00 & 1.55 & 3880 & 10.9 & 38211 & الهند & \\
\hline 0.00 & 0.50 & 1252 & 17.7 & 62158 & شيلى & \\
\hline 0.62 & 1.15 & 2890 & 12.3 & 43015 & 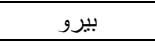 & \\
\hline 0.47 & 0.99 & 2491 & 5.1 & 17816 & مصر - مصر & \\
\hline 0.68 & 1.21 & 3037 & 4.3 & 15230 & البر ازيل & \\
\hline \multirow[t]{3}{*}{0.89} & 1.44 & 3599 & 3.4 & 11998 & ايطاليا & \\
\hline & -- & -- & 13.1 & 46022 & دول أخرى & \\
\hline & \multirow{2}{*}{\multicolumn{2}{|c|}{2505}} & \multirow{2}{*}{\multicolumn{2}{|c|}{350524}} & \multicolumn{2}{|c|}{ اجمالى و اردات هولندا } \\
\hline \multicolumn{3}{|c|}{0.268} & & & \multicolumn{2}{|c|}{ معدل اختراق سوق هولندا } \\
\hline
\end{tabular}

Sources: ITC calculations based on UN COMTRADE statistics. 
توضح بيانات الجدول رقم ( 15 ) أن إجمالى واردات هولندا من العنب الطازج بلغت نحو 351 ألف طن كمنوسط للفترة ( 2016-2014) ، و يتضح أن جنوب افريقيا تأنى فى مقدمة الدول

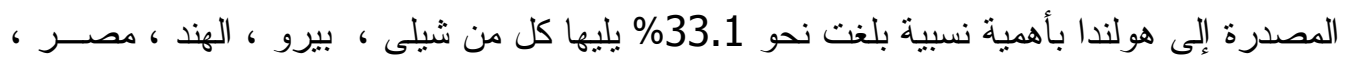

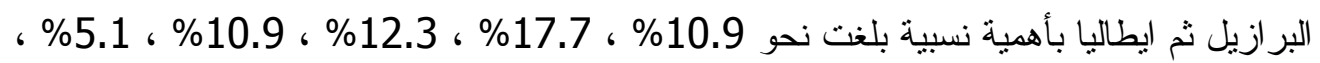
4.3\% ، 3.4\% على الترتيب ـ وقد بلغ المتوسط المرجح لسعر تصدير الطن من العنــب الطــــازج

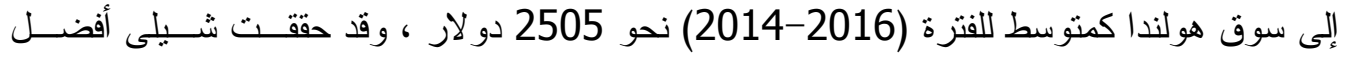

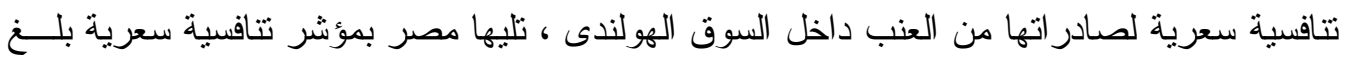
نحو 0.47 فى حين أن النتافسية السعرية للعنب المصرى في وضع أفضل من جنوب افريقيا وبيــرو و البرازيل و ايطاليا الأمر الذى يثير إلى أن مؤشر التتافسية السعرية للعنب المصرى فى سوق هوفيه هولندا

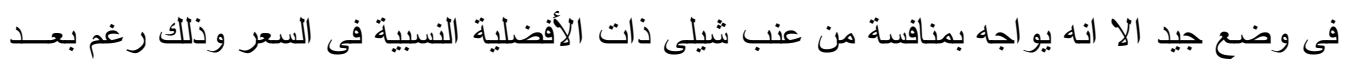
المسافة بينها وبين هولندا مما يستلزم ضرورة الاهتمام بدر اسة هذا السوق كأحد اهم الاسواق الواعدة

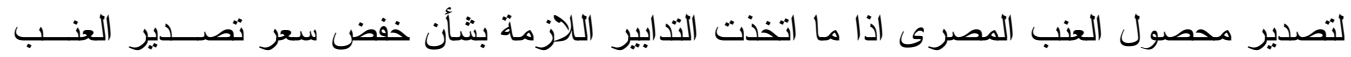
المصرى لمو اجهة اسعار تصدير الدول المتنافسة داخل هذا السوق.

وفيما يتعلق بمؤشر معدل اختراق السوق فقد أوضحت النتائج المبينة بالجدول رقم (15) أن معدل اختر اق محصول العنب المصرى الطازج الى سوق هولندا بلغ نحو 0.268 كمتوسط للفتــرة

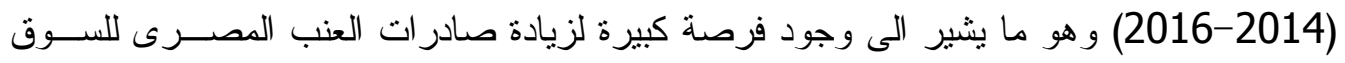

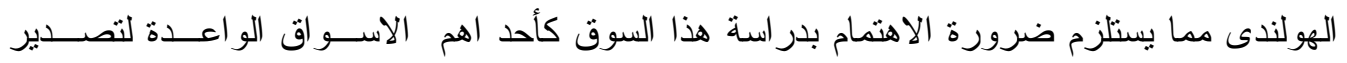

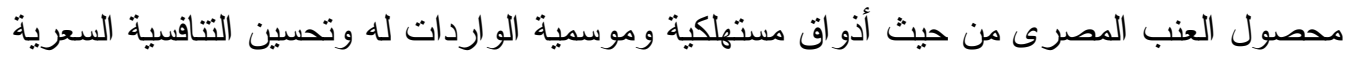
للصادر ات المصرية مقابل اسعار اهم الدول المتتافسة داخل السوق الهولندى. العوامل المؤثرة على كمية الصادرات المصرية من العنب الطازج بسوق المملكة المتحدة:

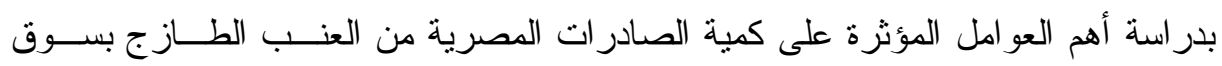

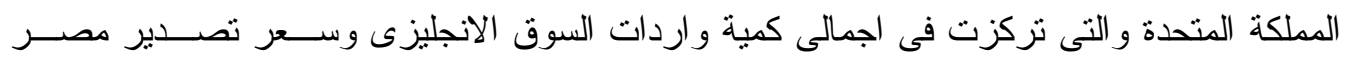

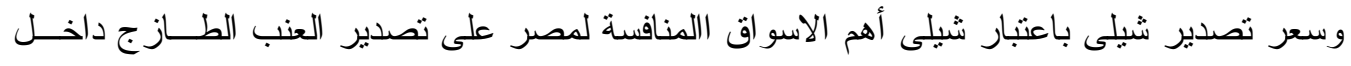

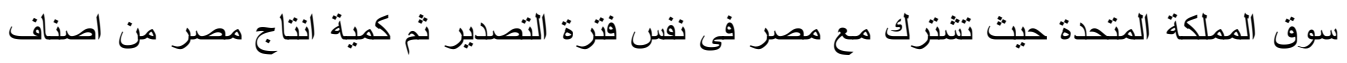

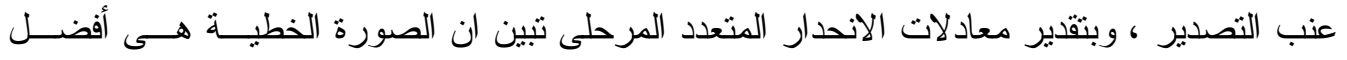

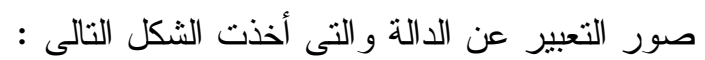
$\mathrm{Y}^{\wedge}=-23546+0.05 \mathrm{X}_{1}^{-3.75} \mathrm{X}_{2}+4.28 \mathrm{X}_{3}{ }^{+0.03} \mathrm{X}_{4}$

$(2.41-)(2.87)(-1.1)(0.92)(2.69)$

$\mathrm{R}^{2}=0.81 \quad \mathrm{~F}=12$

حيث أن : Y^ هى كمية الصادر بات المصرية من العنب الطاز ج لسوق المملكة المتحدة جم1 الىمالى كمية واردات السوق الانجليزى من العنب الطازج سعر تصدير العنب الطازج من مصر الى المملكة المتحدة 
X3 سعر تصدير شيلى الى سوق المملكة المتحدة X3

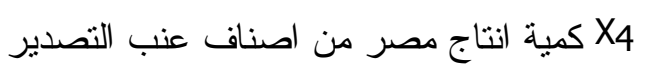
وتنشير معادلة الانحدار المتعدد الى انه كلما زادت كمية واردات السوق الانجليزى بنحو واحد طن تزيد كمية الصادرات المصرية من العنب الطازج بنحو 0.05 طن زيادة معنوية احصائيا ، كما ثنين أن زيادة كمية انتاج اصناف التصدير المصرية بنحو واحد طن يؤدى الى زيادة كمية الصادرات

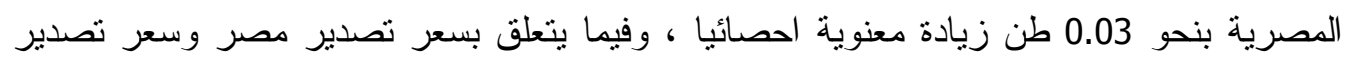

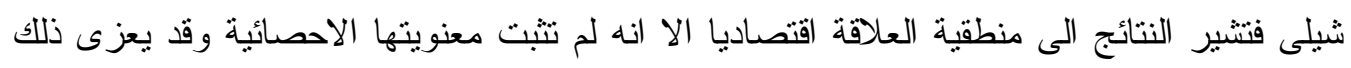
الى ان فترة تصدير العنب المصرى بداية من شهر مايو يكون انتاج العنب فى اوروبا ومعظم

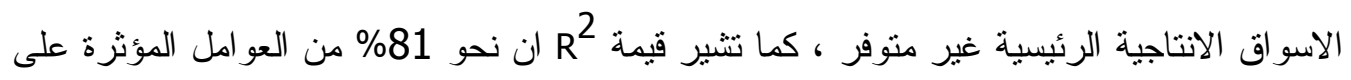

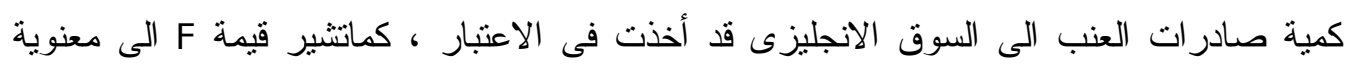
النموذج ككل.

العوامل المؤثرة على كمية الصادرات المصرية من العنب الطازج بسوق هولندا:

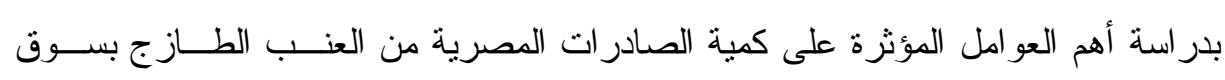

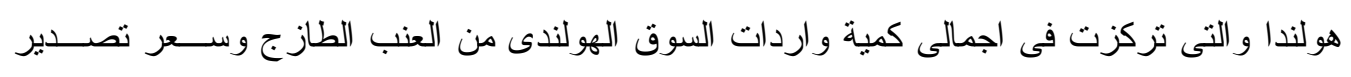

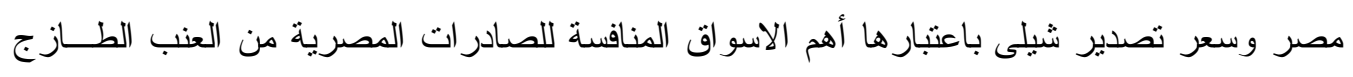

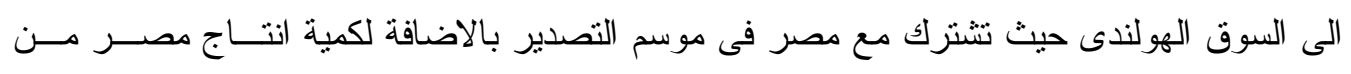

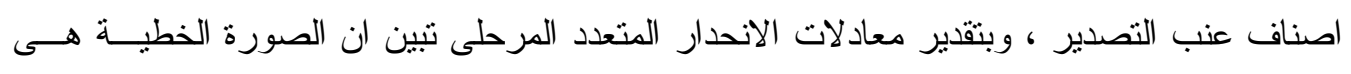
أفضل صور التعبير عن الدالة والتى أخذت الثكل الثالى : $\mathrm{Y}^{\wedge}=172+0.04 \mathrm{X}_{1}{ }^{-0.59} \mathrm{X}_{2}^{-1.9} \mathrm{X}_{3}+0.025 \mathrm{X}_{4}$ (0.56) (4.63) (0.38-) (0.81-) (5.17) $\mathrm{R}^{2}=0.94 \quad \mathrm{~F}=39.7$ حيث أن : Y^ هى كمية الصادر ات المصرية من العنب الطازج لسوق هولندا اجمالى كمية واردات السوق الهولندى من العنب الطازج

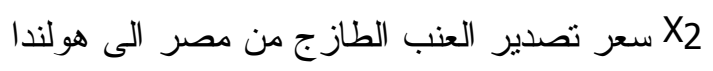

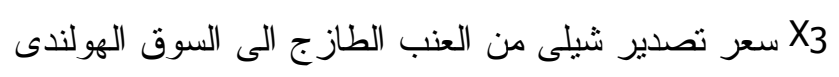

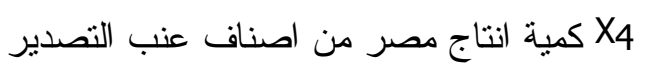

وتتشير المعادلة الى أن كمية الصادرات المصرية من العنب الطازج تزيد زيادة معنوية احصائيا قدرت بنحو 0.04 طن كلما ز ادت كمية واردات السوق الهولندى بنحو طن واحد ، كما تبين ان زيادة

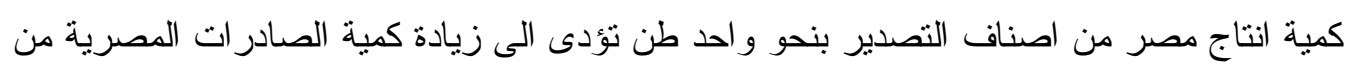
العنب الطازج الى السوق الهولندى بنحو 0.025 طن وقد ثنتت معنوية هذه الزيادة احصائيا ، وفيما

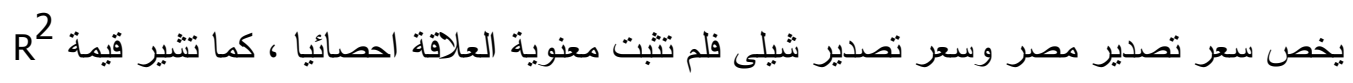

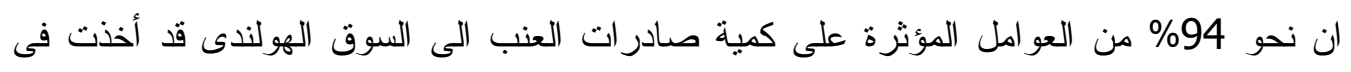

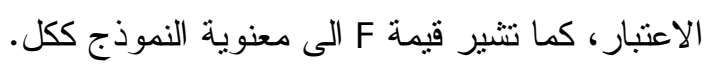




\section{الملخص و التوصيات}

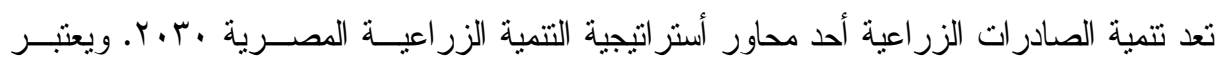

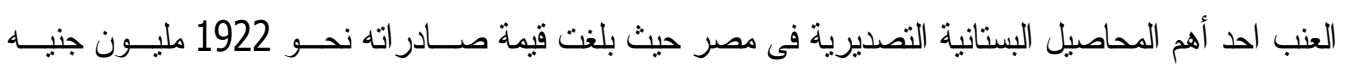

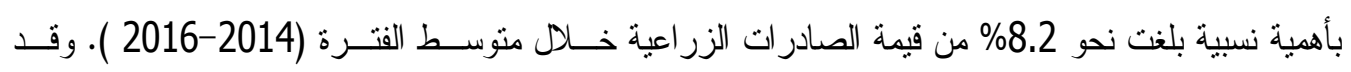

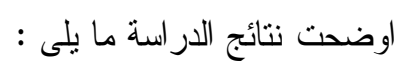
تز ايد المساحة الكلية لاصناف عنب التصدير من نحو 3671 فدان عام 2001 الى نحو 48800 فــــان عـام

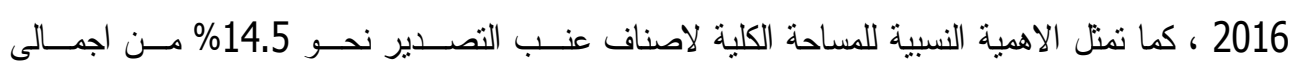

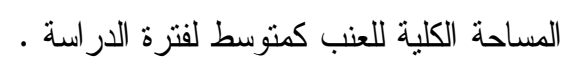
أنثارت نتائج معاملات عدم الاستقر ار لكمية إنتاج أصناف عنب التصدير وكمية صــادرات العنـب وســـر

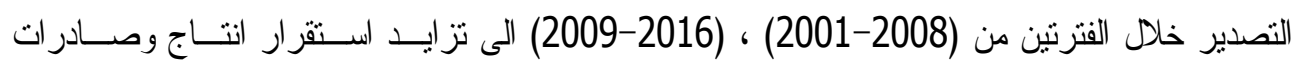

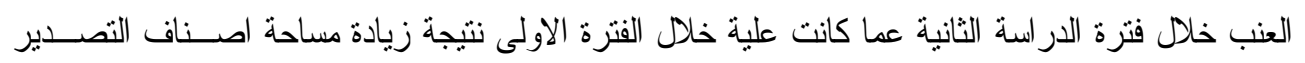
خلال السنوات الاخيرة.

تحتل مصر المرنبة الثالثة عشرة بين دول العالم المصدرة للعنب الطازج بكمية صادر ات بلغت نحو 114 الف طن تنتل نحو 2.6\% كمنوسط للفترة (2016-2014).

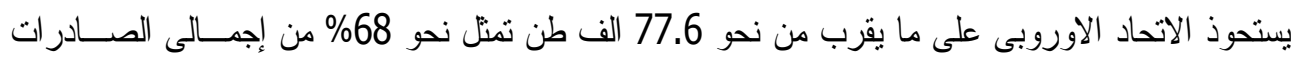

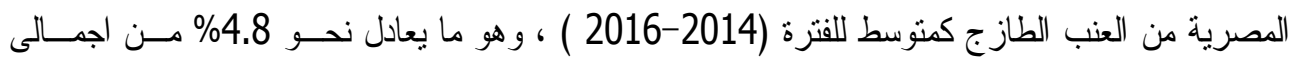
واردات الاتحاد الاوروبى كنتوسط لنفس الفترة. • أهم الدول المستوردة للعنب الطازج المصرى المملكة المتحدة و هولندا بكمية واردات قدرت أهميتها النسـبية

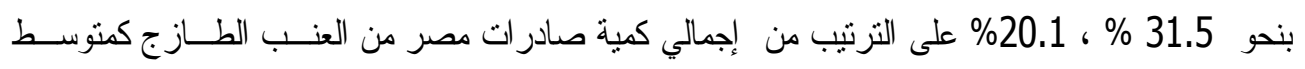
للفترة (2016-2014).

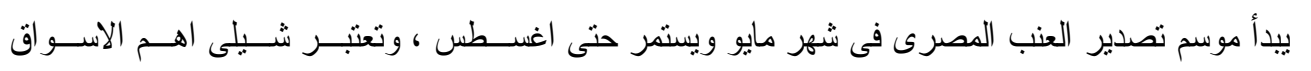

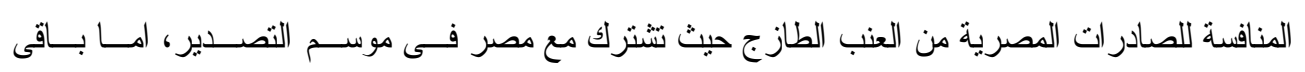

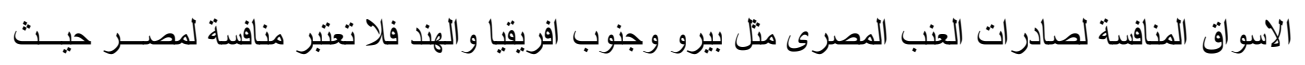
انها لا تشترك معها فى موسم التصدير. بلغت إجمالى واردات المملكة المتحدة من العنب الطازج نحو 264 ألف طــن كمنوســـ للفتــرة ( 2014-

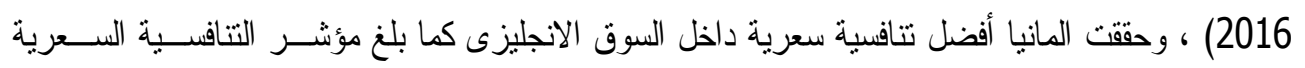

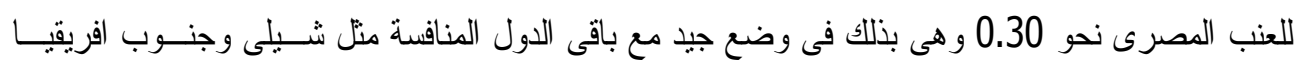

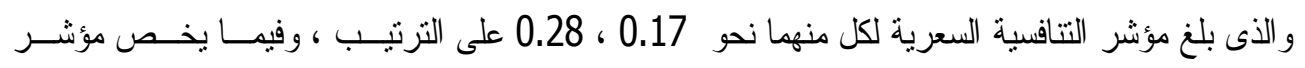

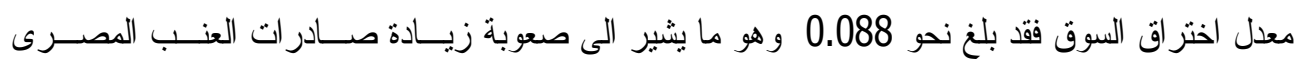
للسوق الانجليزى نتيجة لضيق السوق وصعوبة اختر اقة.

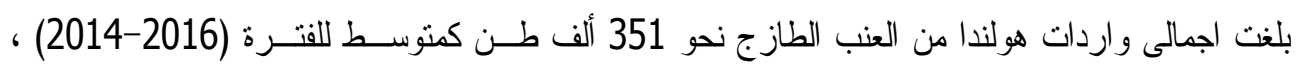

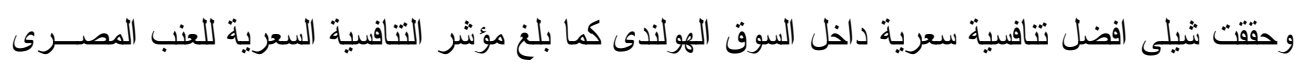


نحو 0.47 ، وفيما بختص بمؤشر معدل اختراق السوق فقد بلغ نحو 0.258 وهو مــا بئسبر الــى وجـود

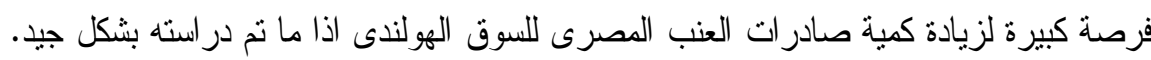

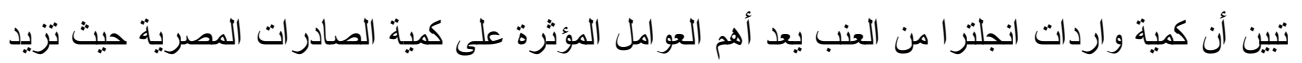

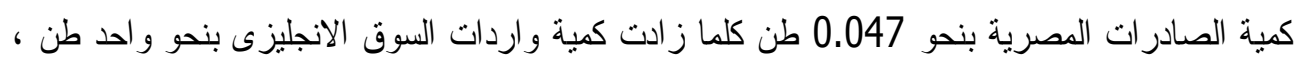

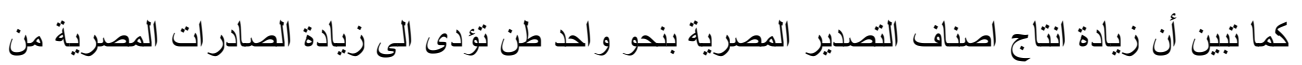
العنب بنحو 0.034 طن ، وفيما يختص بسعر تصدير مصر وسعر تصدير شيلى فلم تثبت معنوية العلاقة بينهم وبين كمية صادرات العنب المصرى للسوق الانجليزى وقد يعزى ذللك الى ان فترة تصدير العنب

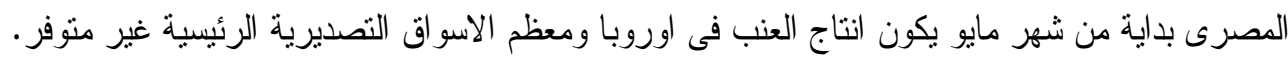

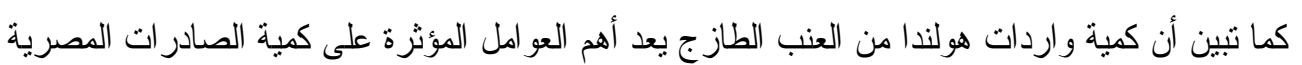

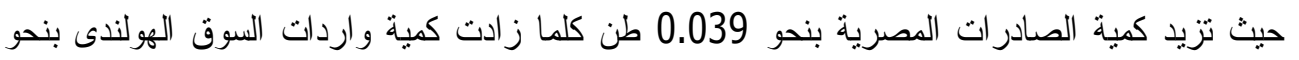

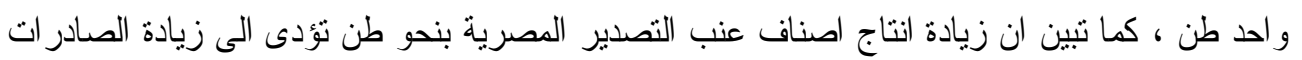
المصرية من العنب بنحو 0.025 ، وفيما يخص سعر تصدير مصر وسعر تصدير شبلى فلم تثبت المعنوية رئي

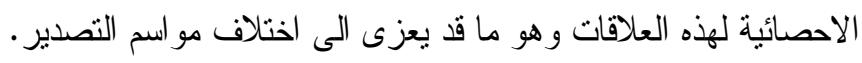

$$
\text { التوصيات }
$$

1- استنياط أصناف مبكرة النضج للاستفادة من فترة الاعفاءات الجمركية المعنوحة للصــادر ات المصـرية مـن

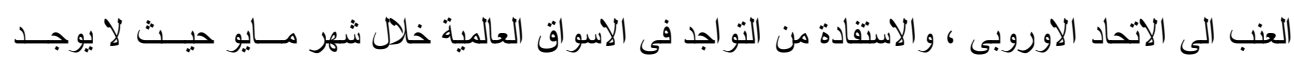

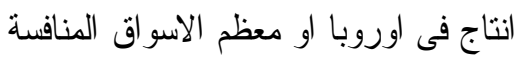

$$
\begin{aligned}
& \text { 2- دراسة الاسو اق الخارجية بشكل جيد وفتح اسواق جليدة }
\end{aligned}
$$

3-الاهتمام بالتدريب و التوعية للمنتجين و المصدرين بمو اصفات الجودة و الاشتر اطات الصحية

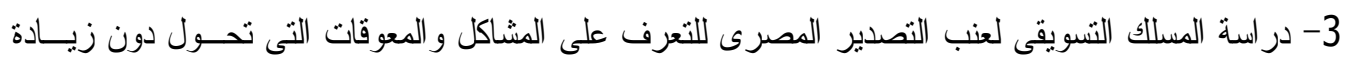

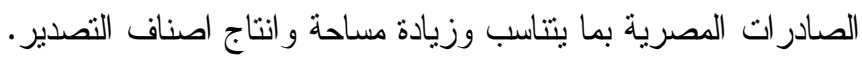

$$
\text { المر اجع المنار }
$$

1- سعد زكى نصار ، الملف الزر اعى فى إتفاق المشاركة المصرية الأوروبية ، الجمعية المصرية للاقتصاد

$$
\text { الزر اعى ، } 2005 \text {. } 200
$$

2-سهير محد القاضى ، دراسة تحليلية لانتاج وتصدير عنب المائدة فى ضوء تكنولوجيا نظم الانتاج

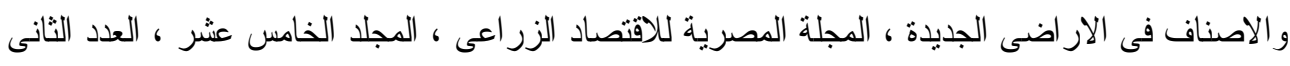

3- Laursen Keld, "Revealed Comparative Advantage and the Alternatives as Measures of International Specialization " , Department of Industrial Economics and Strategy , Copenhagen Business School, Denmark , Internet, 1998.

4- Dr. Memedovic , O. , "On The Theory and Measurment of Comparative Advantage" - An Empirical Analysis of Yugoslav Trade In Manufactures With The OECD Countries , 1970 1986 " , Thesis Published, Amsterdam , 1994.

5- U.S Agency for international Development and Ministry of Economy and foreign trade, "The International Competitiveness of Egypt in Perspective" , Development Economic Policy Reform Analysis , Project (DEPRA), Egypt , Cairo ,1998. 